«COMPETITION AND THE REPUtATIONAL Costs OF LITIGATION»

FELIX VAN MEYERINCK

Vesa PuRsiainen

MARKUS SCHMID

WORKING PAPERS ON FinANCE No. 2021/06

SWISS INSTITUTE OF BANKING AND FINANCE (S/BF - HSG)

APRIL, 2021 


\title{
Competition and the Reputational Costs of Litigation*
}

\author{
Felix von Meyerinck ${ }^{\dagger}$, Vesa Pursiainen ${ }^{\ddagger}$, and Markus Schmid S $^{\S}$
}

April 2021

\begin{abstract}
We study the role of competition in customers' reactions to litigation against firms, using anonymized mobile phone location data. A class action lawsuit filing results in a $4 \%$ average reduction in customer visits to target firms' outlets in the following months. The effect strongly depends on competition. Outlets facing more competition experience significantly larger negative effects. Closer competition matters more, both in terms of geographic and industry proximity. Announcement returns and quarterly accounting revenues around lawsuit filings also strongly depend on competition. Our results suggest that competition is an important component in customers' ability to discipline firms for misbehavior.
\end{abstract}

JEL classification: D12, D43, G14, G30, K42

Keywords: class action lawsuits, corporate misbehavior, competition, reputational costs

\footnotetext{
${ }^{*}$ We appreciate the helpful comments from Yakov Amihud, Efraim Benmelech, Mikael Homanen, William Johnson, Jonathan Karpoff, Peter Limbach, Sibo Liu, Alberto Manconi, Adair Morse, Holger Mueller, Mikael Paaso, Bruno Pellegrino, Steven Davidoff Solomon, Philip Valta, and Petra Vokata as well as seminar participants at the University of St. Gallen. The authors have no conflicts of interest to disclose. All errors are ours.

${ }^{\dagger}$ University of St. Gallen, E-mail: felix.meyerinck@unisg.ch

${ }^{\ddagger}$ University of St. Gallen, E-mail: vesa.pursiainen@unisg.ch

§University of St. Gallen, E-mail: markus.schmid@unisg.ch
} 


\section{Introduction}

Lawsuits against firms tend to be associated with a negative stock price reaction for the target firm.1 Dyck, Morse, and Zingales (2020), among many others, suggest that part of this loss of value is attributable to reputational costs - i.e., the customers of the firm being less inclined to do business with it. Moreover, Karpoff and Lott (1993) argue that the reputational cost constitutes most of the cost incurred by firms accused of fraud. In effect, this means that a substantial part of the mechanism through which lawsuits discipline firms is customers' decision to punish firms that do something they do not approve of. While this seems intuitive, the empirical measurement of this disciplining mechanism is difficult, with most evidence based on indirect measures like share price reactions (e.g., Murphy, Shrieves, and Tibbs, 2009) or anecdotal survey data $2^{3}$

One important aspect that has not been studied is the fact that customers' ability to vote with their feet depends on the availability of alternatives. In other words, it requires competition. While there are numerous studies suggesting that more competition is associated with lower prices (Dafny, Duggan, and Ramanarayanan, 2012; Borenstein and Rose, 1994, Brown and Goolsbee, 2002), better quality (Matsa, 2011), and reduced governance problems (Giroud and Mueller, 2010, 2011), there is, to the best of our knowledge, no research on the role of competition in enforcing discipline through the legal system. If reputational costs represent a large part of the potential punishment from litigation, a lack of competition has the potential to render the legal system ineffective in disciplining firms.

In this paper, we study the role of competition in the reputational costs associated with class action lawsuits. We conjecture that competition is a crucial part of the efficacy of the legal system to discipline firms for wrongdoing. Prior studies suggest that legal penalties from litigation are small relative to the total value loss to firms (e.g., Bizjak and Coles, 1995). This means that much of the potential cost inflicted on firms must come from reputational losses that result in a loss of business. However, such reputational damage is likely to result in financial losses by reduced business volumes only if customers have alternative providers that they can switch to.

\footnotetext{
${ }^{1}$ See, e.g., Bhagat, Brickley, and Coles (1994), Bizjak and Coles (1995), and Gande and Lewis (2009).

${ }^{2}$ For example, a recent CompareCards survey finds that $38 \%$ of all Americans feel that at least one firm is behaving wrongly and are willing to express their disapproval by withholding their dollars.

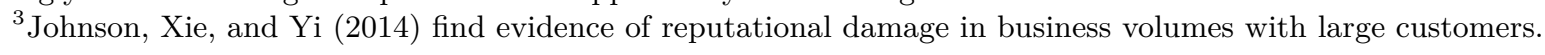


We perform three sets of analyses. First, we analyze changes in monthly customer visits at the outlet level around lawsuit filings. Second, we study stock price reactions to the filings of class action lawsuits. Third, we analyze changes in quarterly accounting revenue around lawsuit filings. The outlet analysis allows a clean identification of reputational effects at a high frequency across a large sample of outlets. Importantly, it also enables constructing detailed measures of the different dimensions of competition at the outlet level ${ }^{4}$ On the other hand, the availability of data for the period from 2018 onward reduces the sample of lawsuits underlying this analysis. The analysis of abnormal returns to the filings of lawsuits allows us to compare our results with prior literature on the shareholder value effect of lawsuits (e.g., Gande and Lewis, 2009), while the analysis of quarterly accounting revenues around lawsuit filings shows that our outlet-level results generalize to the most comprehensive sample of class action lawsuits starting in 1996.

To measure outlet visits, we use aggregated and anonymized mobile phone data from SafeGraph. SafeGraph offers anonymized mobile phone location statistics covering a representative sample of approximately $10 \%$ of all mobile devices in the United States. These data allow us to observe the monthly number of customer visits to each retail outlet. Hence, we are able to observe the changes in retail business volume at a monthly frequency at the outlet level, which helps us overcome many of the data challenges of studies using accounting data. 5 We collect data on 29 class action lawsuits announced between March 2018 and February 2020 and construct a panel dataset of 25,155 outlets belonging to the target firms. As a control group, we use all retail outlets within the same six-digit NAICS industry and the same ZIP code as the target outlets. This allows a clean identification of the effect of the lawsuits on target retail customer volumes, controlling for any changes in local business conditions. To measure competition, we calculate Herfindahl-Hirschman indices (HHI) based on the number of stores of competing firms within the target firm's six-digit NAICS industry and ZIP code. As an alternative measure for competition, we calculate the simple number of alternative outlets in the same industry and location.

Our results provide strong evidence of reputational costs associated with class action lawsuits.

\footnotetext{
${ }^{4}$ Moreover, it does not suffer from the confounding effects that complicate interpretations of abnormal returns or accounting measures. See, e.g., Karpoff (2012) for a discussion on the measurement of reputational losses.

${ }^{5}$ In Table A.1 we report regressions of the logarithm of quarterly revenues on aggregate customer visits across all outlets during a quarter. Results suggest that aggregate customer visits are closely related to firm-level revenue. Hence, declines in shop visits strongly affect company-wide revenues.
} 
The filing of a class action lawsuit is accompanied by a reduction in monthly customer visits of approximately $4 \%$. The reduction in unique visitors is of a similar magnitude. We also find that competition plays a crucial role in the effect of lawsuits on customer behavior, with significantly larger negative effects in outlets facing more competition. The effects of competition are economically large. A one-standard-deviation increase in competition, as measured by the HHI calculated within the same ZIP code and NAICS industry, results in additional four percentage points reduction in customer visits. Similarly, we find that a larger number of alternative firms at the same location is associated with a significantly larger reduction in customer visits, while in the extreme cases with only one competing firm there is no observable reduction in customer visits. We also find that firms are more likely to close outlets following filings of class action lawsuits, and that the effect is stronger when there is more competition. These results are consistent with our prediction that competition facilitates retail customers' disciplining of firms.

Next, we study different dimensions of competition. The levels of competition within the same six-digit and four-digit NAICS industries both matter, but competition at the same two-digit NAICS industries does not have any incremental explanatory power over those two. This suggests that competition matters primarily between firms whose products are close substitutes. We find similar results when looking at competition at different geographic aggregation levels. Competition measured at the ZIP code level has the strongest effect on the reduction in customer visits following a lawsuit. Adding county-level competition does not have incremental explanatory power, but statelevel competition seems to matter as well. In other words, it appears that there are both a very local and a broad, state-level, component of market power.

Finally, we find that the largest reductions in customer visits take place near the firms' headquarter locations. This is consistent with filings of class action lawsuits being most salient near the firm headquarters, possibly driven by more media coverage. Furthermore, the negative effect of lawsuits is larger in areas with more religious and, in particular, more protestant populations, areas with stronger social norms, measured by the social capital index of Lin and Pursiainen (2020), and in more Republican-voting counties. These demographic differences are likely to be proxies for customers' willingness to punish firms for wrongdoing and to vote with their feet.

We then focus on the stock price response to class action lawsuits. In a comprehensive sample of 
more than 3,000 class action lawsuits filed since 1996, we find that the filing of a class action lawsuit is associated with large negative stock returns. In particular, the average cumulative abnormal return $(\mathrm{CAR})$ is $-10 \%$ over a window of ten days prior to one day after the filing date. This finding is consistent with prior literature (e.g., Gande and Lewis, 2009). Supporting our findings from the sample of outlet visits, we find that competition is an important determinant of the announcement return. Firms facing more competition experience significantly more negative abnormal returns around the filings of class action lawsuits. This finding is robust to using various measures of competition. It is also statistically and economically significant. A one-standard-deviation increase in competition, as measured by the HHI calculated within the same six-digit NAICS industry, results in one percentage point lower cumulative abnormal returns.

To confirm that our results on customer visits are not confined to the sample of class action lawsuits that overlaps with the SafeGraph data, we also perform an analysis of quarterly accounting revenues using a sample of around 3,800 class action lawsuits filed since 1996. For every firm that is a target of a lawsuit, we use a control group consisting of all other firms in the same six-digit NAICS industry. Relative to the control firms, targets of class action lawsuits experience a $9-10 \%$ reduction in revenue in the year following the filing of the lawsuit. As with outlet visits and abnormal returns around lawsuit filings, the effect is dependent on competition, with significantly larger reductions in revenue observed at firms in more competitive industries. A one-standard-deviation increase in competition, as measured by the HHI calculated within the same six-digit NAICS industry, is associated with two percentage points in additional revenue losses.

Generally, our results suggest that retail customers reduce their visits in the outlets of firms targeted in class action lawsuits. To do so, they need to be aware of either the lawsuit or the misconduct that led to the lawsuit. We study two possible information channels that may increase the salience of lawsuits to consumers: media coverage and stock investments. First, using data from Factiva, we find that media attention increases substantially from the month before until one month after the filing and then decreases to levels similar to or below the months preceding the lawsuit. Second, we study stock holdings as an alternative channel through which retail customers might learn of lawsuits or the events leading up to them. Keloharju, Knüpfer, and Linnainmaa (2012) show that retail investors' investment decisions are influenced by their product market choices. As 
retail investors have strong incentives to monitor the companies they own or consider investing in, they may learn of a lawsuit or the misconduct that caused it through their company screening as investors and then react both as consumers and as investors. Consistently, using data from Robinhood, a large retail brokerage house, we find a substantial reduction in the number of retail investor accounts holding stocks of firms targeted by class action lawsuits around the filing date. These significant shifts in media coverage and retail investor holdings suggest that class action lawsuits are salient events for retail customers.

Taken together, we uncover strong and consistent evidence that the ability of customers to discipline firms in case of misconduct strongly depends on the competitive environment. Using different methodologies and across different samples, we find the same patterns of a negative average effect of the filing of class action lawsuits and this effect depending on the level of competition.

Our findings provide important new insights into the importance of competition for the proper functioning of the legal system. As a large part of the effective punishment from lawsuits comes in the form of reputational damage (e.g., Karpoff and Lott, 1993), our results suggest that lack of competition may render the legal system ineffective in deterring corporate misconduct. This might suggest that legal punitive damages need to increase substantially with an increase in market power to maintain the intended deterrent effect. Concerns over excessive market power are mounting as industries have grown more concentrated and profitable, both in the U.S. Covarrubias, Gutiérrez, and Philippon, 2019, Grullon, Larkin, and Michaely, 2019) and globally (De Loecker and Eeckhout, 2018: Bae, Bailey, and Kang, 2021).$^{6}$ Recent concerns about the abuse of monopolistic market power, in particular, by shareholders (e.g., Azar, Schmalz, and Tecu, 2018) and tech firms (e.g., Shapiro, 2019), also led to a surge in antitrust investigations in the U.S. as well as in Europe.7

Our results on the differential effects of competition measured at various levels may also have important implications in other contexts. We show that competition measured at the micro level appears significantly more important than competition measured at a broader level, both in terms geography and industry definitions. This suggests that research on competition benefits from

\footnotetext{
[ Kahle and Stulz (2017) report some stylized facts. In the U.S., there were $25 \%$ more public corporations in 1975 than there were in 2015. In 1975, the top 109 firms earned 50 percent of the total earnings of all U.S. public firms; in 2015, half of the total earnings were generated by just 30 firms. Similarly, 94 firms owned half of the total assets of all U.S. public firms in 1975 , but only 35 did so in 2015.

${ }^{7}$ See also "Common ownership of shares faces regulatory scrutiny", Financial Times, January 22, 2019; "Justice Department Hits Google With Antitrust Lawsuit", Wall Street Journal, October 20, 2020.
} 
studying settings in which market structures can be observed at granular levels.

Our study is also closely related to the literature on shareholders' ability to influence firms through exit (see, e.g., Admati and Pfleiderer, 2009, Bharath, Jayaraman, and Nagar, 2013) 8 Broccardo, Hart, and Zingales (2020) show theoretically that the exit options of investors and consumers - two important stakeholder groups - share similarities as they represent an effective means of pressuring firms. In a related study of customers punishing firms, Homanen (2018) finds evidence of depositors disciplining banks by withdrawing their deposits.

We also make several contributions to the literature on the reputational effects of class action lawsuits and corporate misconduct more broadly. First, our outlet-level analysis provides the most direct evidence to date of customers' decision to discipline firms following a lawsuit. Prior studies focus either on returns (e.g., Bizjak and Coles, 1995, Gande and Lewis, 2009) or accounting performance (e.g., Murphy et al., 2009; Johnson et al., 2014) around lawsuit filings. Hence, they suffer from potential alternative explanations, such as increases in bankruptcy costs, which makes it difficult to measure the impact of customer response in a clean fashion. We are able to measure customer visits directly at the outlet level, thus avoiding these problems. Second, our finding that the competitive environment of the target firm in a lawsuit is a key determinant of the reputational losses is novel and has important implications for identifying reputational effects in other contexts as well.

\section{Relevant literature}

\subsection{Competition and market power}

Competition is important for many aspects of functioning markets. Economic theory suggests that market power increases prices, reduces output, and decreases general social welfare (see, for instance, Tirole, 1988). Several empirical studies suggest a positive relationship between concentration and prices in various industries, including healthcare (Dafny et al., 2012), airlines (Kim and Singal, 1994 Borenstein and Rose, 1994), life insurance (Brown and Goolsbee, 2002), and many others. Matsa (2011) provides evidence that competition increases quality in the supermarket industry,

\footnotetext{
${ }^{8}$ See Edmans (2014) for an overview of this literature.
} 
with the risk that customers will switch stores providing competitors with a strong incentive to invest in product quality.

Competition affects firms in various ways. Product market competition can reduce managerial slack (Hart, 1983), thereby substituting good corporate governance (Giroud and Mueller, 2010, 2011). Aghion, Bloom, Blundell, Griffith, and Howitt (2005) show that competition affects innovation. Raith (2003), Gaspar and Massa (2006), and Irvine and Pontiff (2009) document that higher competition is correlated with higher risk, while Hou and Robinson (2006) show that firms in more concentrated industries earn lower returns. Valta (2012) reports that competition increases the cost of debt. Jung and Subramanian (2017) develop a structural industry equilibrium model and show that CEO talent matters more in more competitive markets. Chod and Lyandres (2011) theoretically show that the strategic benefit from being public is larger in more competitive markets and provide empirical support for their model predictions. Evidence by Nickell (1996) indicates that stronger competition is associated with a higher rate of total factor productivity growth. Ashenfelter and Hannan (1986) show that competition limits firms' ability to discriminate employees based on gender.

The consequences of reduced competition have come to the fore recently as U.S. industries have grown more concentrated and profitable (Covarrubias et al., 2019, Grullon et al., 2019). Similarly, De Loecker and Eeckhout (2018) document an increase in market power globally from 1980 to 2016, with markups having risen most in North America and Europe, and least in Latin America and Asia. Increases in market power are known to be followed by decreases in economic growth, capital allocation efficiency, and innovation activity (Bae et al., 2021). Recent concerns about the abuse of monopolistic power, in particular, by shareholders influencing entire industries (e.g., Azar et al. 2018) and tech firms (e.g., Shapiro, 2019), led to a surge in antitrust investigations in the U.S. as well as in Europe.

\subsection{The reputational costs of corporate misconduct}

A large literature studies the role of reputation in disciplining firms (see, e.g., Karpoff (2012), for an overview). Karpoff and Lott (1993) argue that the reputational cost constitutes most of the cost incurred by firms accused of fraud. Karpoff and Lott (1999) find that punitive lawsuits decrease the 
values of defendant equity market value by amounts that exceed settlement or jury verdict amounts, indicating that punitive lawsuits impose reputational costs on defendants and their shareholders. Alexander (1999) shows that offenses harming only private parties and not government tend to be addressed largely through civil or market-based and not criminal sanctions.

A number of studies focus on the share price impact of the filing of lawsuits. Bhagat et al. (1994) study inter-firm litigation and find that the target firm experiences a negative average return of around 1\%, while the plaintiff experiences no corresponding gains. Similarly, Bizjak and Coles 1995 find that inter-firm antitrust litigation results in aggregate wealth losses, partly explained by financial distress, behavioral constraints, and follow-on suits. Gande and Lewis (2009) show that shareholders capitalize part of the losses from shareholder class action lawsuits prior to the lawsuit filing date, and hence, that studies focusing on the filing day underestimate the losses incurred. Bhagat, Bizjak, and Coles (1998) find that the characteristics of the lawsuit, such as the legal issue and type of opponent, as well as firm characteristics, such as firm size and proximity to bankruptcy, explain cross-sectional variation in the wealth effects of corporate lawsuits.

The evidence on the effect of litigation on firms' financial performance is more limited. Murphy et al. (2009) find evidence of decreases in earnings and increases in risk following allegations of corporate misconduct, although their results appear sensitive to the metric used. Johnson et al. (2014) find that reputational damages for fraud result in a decline in the firm's operating performance through increased selling costs and that reputational losses estimated from an announcement return approach reflect the actual decrease in the revenue of a fraudulent firm.

Karpoff, Lee, and Martin (2008) find that individuals identified as responsible parties for all Securities and Exchange Commission (SEC) and Department of Justice (DOJ) enforcement actions for financial misrepresentation are very likely to lose their jobs and many face criminal charges and penalties. Similarly, Desai, Hogan, and Wilkins (2006) show evidence of reputational penalties to managers of firms announcing earnings restatements in the form of management turnover and subsequent employment prospects. Fich and Shivdasani (2007) find that, following a financial fraud lawsuit, outside directors do not face abnormal turnover on the board of the sued firm but experience a significant decline in the number of other board seats held. Brochet and Srinivasan (2014) show that independent directors who are named as defendants when investors sue firms for 
securities fraud obtain more negative votes and are more likely to leave the sued firm. In contrast, Helland (2006) finds limited evidence of a negative effect on officers or directors of a company associated with allegations of fraud.

While litigation can be an important disciplining mechanism, it can also have unintended real consequences. For example, Arena and Julio (2015) find that the risk of securities class action litigation alters corporate savings and investment policy, with firms having greater exposure to securities litigation holding significantly more cash in anticipation of future settlements and other

related costs. Kempf and Spalt (2020) show that securities class action lawsuits can constitute an obstacle to valuable corporate innovation. This is because valuable innovation output makes firms particularly vulnerable to costly low-quality class action litigation. Litigation risk affects the value and number of patents filed, suggesting that firms take into account that risk in their innovation decisions. Lin, Liu, and Manso (2020) find that the external pressure imposed by shareholder litigation discourages managers from engaging in explorative innovation activities.

\section{Data and methodology}

\subsection{Class action lawsuits}

We begin our sample construction by retrieving all securities class action lawsuits from the Securities Class Action Clearinghouse (SCAC) database maintained by Stanford Law School. The database covers all securities class actions filed in federal court after the Private Securities Litigation Reform Act of 1995 came into effect. Our initial sample contains 5,883 lawsuits filed between 1996 and late 2020. From this sample, we drop lawsuits involving financial firms and lawsuits involving firms headquartered outside of the U.S. For the different empirical analyses that we conduct in this study, we merge this sample with different datasets.

\subsection{Retail customer response to class action lawsuits}

We examine the customer response to class action lawsuit filings using aggregated mobile phone data from SafeGraph. SafeGraph is a company that produces anonymized mobile phone location statistics. SafeGraph tracks 18.75 million devices, which represents approximately $5.6 \%$ of the entire 
U.S. population and about $10 \%$ of all U.S. mobile devices. Based on SafeGraph's analysis of its user base, it posits that its customers are representative of the general U.S. population with regards to income, age, and other demographics. The data are used in studies of social distancing during the SARS-CoV-2 pandemic (see, e.g., Bizjak, Kalpathy, Mihov, and Ren, 2020, Charoenwong, Kwan, and Pursiainen, 2020; Weill, Stigler, Deschenes, and Springborn, 2020), and more recently also to measure consumer responses to firm's actions (see, e.g., Painter, 2020; Gurun, Nickerson, and Solomon, 2020). The data include monthly number of visits and visitors at the outlet level. The coverage of SafeGraph's outlet-level data starts in January 2018.

We identify outlets of firms involved in class action lawsuits by manually searching the SafeGraph database for outlets of firms involved in a class action lawsuit in the SCAC database. We restrict the sample to lawsuits filed on or after March 1, 2018. This enables us to maintain at least two monthly pre-treatment observations for all lawsuits. Moreover, we disregard lawsuits filed after February 29, 2020. This avoids an impact of the SARS-CoV-2 pandemic on our results 99 Finally, we retain only outlets of firms involved in class action lawsuits for which we can match control outlets as described below. Overall, this results in a treatment sample comprising 25,155 distinct outlets associated with 29 class action lawsuits.

We construct the control sample by selecting all monthly observations of outlets in the same ZIP code and six-digit NAICS industry as the treated outlets. This yields a matched control sample comprising 123,129 distinct outlets. Table A.2 in the appendix reports the number of treated and control outlets for each class action lawsuit. Figure A.1 shows the spatial distribution of outlets across the U.S.

We compute several measures of competition at the outlet level. As our main measure, we calculate the HHI based on the percentage number of outlets each firm has in the filing year, ZIP code, and six-digit NAICS industry as the treated outlet.10 We also vary the calculation of the HHI along two dimensions to study different dimensions of competition. To analyze different levels of competition at the industry level, we compute the HHI within the filing year and ZIP code but at the four-digit NAICS industry and two-digit NAICS industry. To analyze different levels of

\footnotetext{
${ }^{9}$ The first death attributed to the SARS-CoV-2 pandemic was reported in the U.S. on February 29, 2020.

${ }^{10}$ We rely on the North America Industry Classification System (NAICS) rather than the Standard Industry Classification (SIC) system because SafeGraph only provides NAICS industry codes. In later analyses, we also use the text-based network industry classification (TNIC) system of Hoberg and Phillips $(2010,2016)$
} 
geographic competition, we estimate the HHI within the filing year and six-digit NAICS industry but at the county and state level. Finally, we calculate the total number of firms with stores in the filing year, six-digit NAICS industry, and ZIP code as an alternative measure of competition.

\subsection{Stock market response to class action lawsuits}

We analyze changes in shareholder value around filings of class action lawsuits using stock price data from the Center for Research in Security Prices (CRSP). We do so for the entire sample of class action lawsuits as provided by the SCAC. In this analysis, we additionally drop lawsuits whose outcome are unknown at the time of writing ("ongoing") and lawsuits that are remanded to another court.

We estimate changes in shareholder value around the filing date by employing standard event study methodology. To this end, we augment the sample of class action lawsuits from the SCAC database with security and firm identifiers from CRSP. For each class action lawsuit, we compute CARs as the sum of daily abnormal returns from ten trading days before the event date to one trading day after the event date where the filing date of a security class action lawsuit marks the event date. This event window follows prior literature, in particular Gande and Lewis (2009). Daily abnormal returns are calculated as the observed return less a predicted return. The latter is the predicted return of a market model regression in which daily returns are regressed on daily value-weighted index returns provided by CRSP over a 250-day estimation window that ends eleven trading days prior to the event date 11 We require non-missing stock return observations in the event window and at least 90 non-missing return observations in the estimation window to run the market model regression. This results in a sample of 3,322 class action lawsuits. To mute the impact of outliers, we winsorize all abnormal return measures at the $1^{\text {st }}$ and $99^{\text {th }}$ percentiles.

As in the outlet analysis, we use different measures for a firm's competitive environment. First, as a measure of industry concentration, we compute the HHI for a firm's six-digit NAICS industry in the fiscal quarter that precedes the filing date based on positive quarterly revenue. Second, we count the number of distinct competing firms in a firm's six-digit NAICS industry with positive revenue.

\footnotetext{
${ }^{11}$ Our results are very similar if we use CRSP's equally-weighted market return as a market return proxy, if we use a Fama and French (1993) three or Carhart (1997) four-factor model, or if we use a market-adjusted model instead of a market model.
} 
Third, we set a dummy equal to one for firms with the lowest possible industry concentration, i.e., for firms with no competing firm in its six-digit NAICS industry. We also retrieve two measures of industry concentration and market power based on firms' pairwise similarity scores obtained from text analysis of firms' product descriptions in their annual 10-K filings. Hoberg and Phillips (2010. 2016) show that their text-based industry classification (TNIC) improves upon SIC and NAICS industries in explaining firm characteristics such as profitability, Tobin's Q, and dividends. As a fourth measure of competition, we thus obtain the revenue HHI based on Hoberg and Phillips' TNIC for the firm's fiscal year. Fifth, we employ Hoberg and Phillips' firm-level measure of product market power, with lower values indicating a lower substitutability of a product with competitors' products.

\subsection{Revenue response to class action lawsuits}

We estimate the response of the operating performance to class action lawsuit filings by studying quarterly revenues from Compustat. Again, we utilize the entire sample of class action lawsuits as provided by the SCAC. As in the analysis of stock returns, we also drop lawsuits whose outcome are unknown at the time of writing ("ongoing") and lawsuits that are remanded to another court. This results in a sample comprising 2,828 distinct treated firms being the target of at least one securities class action lawsuit.

Consistent with the construction of the matched control sample in the outlet-level analysis, we match each quarterly lawsuit-firm observation with all quarterly observations of firms active in the same six-digit NAICS industry ${ }^{12}$ This yields a matched control sample comprising 10,786 distinct firms.

The measures of competition that we employ in this analysis are the same as those used in the analysis of changes in shareholder value around filings of class action lawsuits described above.

\footnotetext{
${ }^{12}$ In contrast to the outlet-level analysis, we only match based on six-digit NAICS industries and not based on ZIP codes because the sample of potential control firms is not sufficiently populated to match on both six-digit NAICS industries and ZIP codes.
} 


\section{Competition and retail customer response to class action law- suits}

This section contains our empirical analysis of the retail customer response to class action lawsuits. First, we describe the matched sample of outlets used in this analysis. Next, we analyze the response of retail customers to class action lawsuits. Third, we study the impact of local competition on retail customers' ability to hold firms accountable for corporate misbehavior. Finally, we turn our attention to other outlet characteristics that influence retail customers' response to class action lawsuits.

\subsection{Descriptive statistics}

Table 1 reports descriptive statistics for the monthly outlet panel. On average, close to 270 distinct customers pay around 400 visits to each outlet in our sample per calendar month ${ }^{13}$ The average likelihood that a store closes in a given month is around $0.11 \%$. An outlet in our sample on average has around 13 other competing firms (defined based on brand identifiers in SafeGraph) in the same six-digit NAICS industry, ZIP code, and month. The average HHI for the outlets in our sample is 0.14 . As measured by different HHIs, industries become less concentrated if measured at less granular industry definitions (mean of 0.10 and 0.07 for the four-digit and two-digit NAICS industries, respectively) or at larger geographic units (mean of 0.11 and 0.10 at the county and state level, respectively).

\subsection{Results}

To analyze how retail customers respond to class action lawsuits, we study monthly customer visits to outlets belonging to a firm that is the target of a class action lawsuit. As control group, we use outlets in the same industry and ZIP code. We first perform a monthly regression analysis specified

\footnotetext{
${ }^{13}$ Note that this is the number of visits and visitors tracked by SafeGraph, not the total number of visits and visitors.
} 
as:

$$
\ln \left(\text { Visits }_{i, s, t}=\beta_{t} \times \text { Treatment }_{i, s} \times \text { Event mont }_{i, t}+\alpha_{i, s}+\alpha_{s, j, k, t}+\epsilon_{i, s, t},\right.
$$

where $i$ indexes an outlet, $s$ a lawsuit, $t$ a month, $j$ an industry, and $k$ a ZIP code. Visits is the monthly number of visits of an outlet. Treatment is a dummy indicating whether an outlet belongs to a firm that is the target of a lawsuit. Event month are dummies indicating months relative to the filing month. We include interacted lawsuit and outlet fixed effects as well as interacted lawsuit, industry, ZIP code, and month fixed effects. These fixed effects ensure that we compare within outlet changes in visits to treated outlets with changes of visits to control outlets in the same month that are active in the same industry and location. Therefore, these fixed effects control for a range of characteristics, including the time trend, industry shocks coinciding with the filing of the lawsuit, and time-varying ZIP code characteristics. Moreover, they absorb the stand-alone Treatment dummy as well as the stand-alone Post dummy.

Figure 1 shows the estimated monthly regression coefficients for the interacted treatment-month dummies, relative to the month preceeding the filing month of a lawsuit (omitted in the regression). Generally, customer visits of firms targeted in class action lawsuits tend to start falling already before the announcement, but insignificantly so. This is not surprising as we cannot directly observe instances of misconduct, but use filings of a class action lawsuit a proxy for misconduct. In some cases of misconduct, information related to firms' wrongdoing may transmit into the market before a lawsuit is filed.

To facilitate further cross-sectional analysis of heterogeneity in the reputational effect across treated stores, we define an indicator variable that equals one for the filing month and the five months after (Post) and perform an analysis of the interaction term of this dummy with the Treatment dummy. This analysis is specified as:

$$
\ln \left(\text { Visits }_{i, s, t}=\beta_{1} \times \text { Treatment }_{i, s} \times \text { Post }_{i, t}+\beta_{2} \times \text { Post }_{i, t}+\alpha_{i, s}+\epsilon_{i, s, t} .\right.
$$

The results are reported in Table 2. In Column 1, the coefficient on the interaction term shows that outlets belonging to a firm that is the target in a class action lawsuit experience a reduction 
in visits of $-5.4 \%$ in the filing month and the five months following the filing month of the lawsuit. With $-6.6 \%$ and $-3.8 \%$, estimates remain economically meaningful and statistically significant if we add month fixed effects, as in Column 2, as well as interacted lawsuit, ZIP code, six-digit NAICS industry, and month fixed effects, as in Column 3. Moreover, the positive and significant coefficient on the dummy variable Post, which is equal to one for the filing month and the five months after, is consistent with positive spillovers to competitors. In Column 2, which includes month fixed effects, we find that the sample of matched control outlets experiences an increase in shop visits of about $1.8 \%$, while treated outlets suffer a decline in visits of $-6.6 \%$ relative to control outlets, or $-4.8 \%$ overall. Taken together, these results provide strong evidence of reputational costs of corporate misbehavior.

To analyze the impact of local competition on store visits, we augment the regression from Column 3 of Table 2 with a triple interaction term, obtained by multiplying the existing interaction term between the Treatment and the Post dummy with different measures of local competition. These additional interaction terms allow us to gauge the incremental impact of customers' local ability to substitute visits of outlets belonging to the same firm targeted in the same class action lawsuit with visits of outlets of a competing firm.

The results are reported in Table 3 . In Column 1, we use a very granular form of the HHI, estimated at the six-digit NAICS industry and ZIP code level, as a proxy for local competition. We continue to find a negative reputational effect following filings of class action lawsuits on store visits, as indicated by the significantly negative coefficient on the interaction term between the Treatment dummy and the Post dummy. Consistent with the conjecture that lower competition mutes the disciplining effect of class action lawsuits, the coefficient on the triple interaction term is positive and highly significant. Economically, this result has sizeable implications: A one-standarddeviation increase in local competition, as measured by the HHI, results in an additional four percentage points reduction in customer visits compared to stores in the same month that belong to the same firm targeted in the same lawsuit. This result implies that customers' ability to punish firms for wrongdoing critically hinges on the availability of outlets of firms that compete locally.

Next, we study whether different levels of competition matter differently. To do so, we vary the industry granularity at which we measure competition to the four-digit and two-digit NAICS 
industries. Results in Columns 2 and 3 show that less competition within the same four-digit and two-digit NAICS industries both reduce the ability of customers to substitute visits of outlets of firms accused of wrongdoing with visits of outlets of competing firms. However, when competition measures at all three levels of industry granularity are included jointly as explanatory variables, as in Column 4, we obtain coefficients that are monotonically decreasing the less granular the industry measures are, with competition at the two-digit NAICS industry level having no incremental explanatory power beyond the two more granular measures of industry competition. This implies that the ability of customers to substitute visits of outlets of firms accused of wrongdoing is facilitated if the offerings of competing outlets are more similar.

We also vary the geographic dimension of competition. To this end, we compute the HHI based on six-digit NAICS industries at the county level and state level. The results show that higher competition at the ZIP code level (Column 1), county level (Column 5), and state level (Column 6) intensifies the reduction in store visits following filings of class action lawsuits. However, when all three measures of competition are included jointly, as in Column 7, we find that competition measured at the most granular (ZIP code) level has the strongest effect on the reduction in customer visits, followed by competition measured at the least granular (state) level. In contrast, adding county-level competition does not have incremental explanatory power. Hence, there is both a local (i.e., ZIP code-level) and a broader (i.e., state-level) component of market power.

Next, we analyze alternative measures of competition at the ZIP code level. First, we count the number of other brands within the same six-digit NAICS industry and ZIP code. If added to the regression model in the form of a triple interaction term, as in Column 8, we find that a larger number of alternative brands at the same location is associated with a significantly larger reduction in customer visits 14 As a second alternative measure of local competition, we construct a dummy that is equal to one for outlets with only one competing brand being active in the same sixdigit NAICS industry and ZIP code, which corresponds to the weakest form of local competition possible in our setting 15 Results in Column 9 show that in such a concentrated market, the

\footnotetext{
${ }^{14}$ The coefficient on the triple interaction term between the Treatment dummy, the Post dummy, and the number of competing brands remains negative and significant if we take the logarithm of the number of the number of competing brands.

${ }^{15}$ The reason why we cannot estimate the effect of having no competitor - in reality the most extreme case of (monopolistic) market power - is due to the high-dimensional fixed effects that we employ. In particular, we match control outlets to treated outlets based on month, six-digit NAICS industry, and ZIP code, so including Lawsuit $\times$
} 
baseline reputational effect of a decline in outlet visits of $5.6 \%$ is completely offset (the coefficient on the triple interaction term is $6.8 \%$ ). Taken together, these results using alternative measures of competition at the ZIP code level underscore that competition is a necessary condition for the ability of customers to discipline firms.

We also test the robustness of our findings using different outcome variables. As alternative proxies for the customer response, we use the logarithm of unique outlet visitors (instead of outlet visits) as well as a dummy variable indicating a store closure. For each alternative dependent variable, we first replicate the test of an adverse reputational effect from filings of class action lawsuits (Table 2) and the then replicate the test of an amplifying effect of competition (Table 3). For brevity, we only report results for our three main measures of competition at the outlet level (HHI at the ZIP code and six-digit NAICS industry, the number of competing brands, and a dummy variable set equal to one if an outlet has only one competing brand).

The results are reported in Table 4. In Panel A, we use the logarithm of unique outlet visitors in a month as dependent variable. In Columns 1 to 3, we document a negative customer response to class action lawsuits that is of similar magnitude as in our main regression in Table 2 and statistically significant at the $1 \%$ level. In Columns 4 to 6 , we also find consistent evidence with our main regression in Table 3 as the negative reputational effect is amplified by competition. In Panel B, we use a dummy variable that we set equal to one if a store closes next month as dependent variable. In Columns 1 and 2, we find a positive and significant loading on the interaction term between the Treatment dummy and the Post dummy. In Column 3, which shows results from the tightest specification including interacted lawsuit, location, industry, and month fixed effects, we find an insignificant coefficient on the interaction term. Finally, we test whether a firm targeted in a lawsuit is more likely to close outlets in locations with a more atomistic market structure. In Columns 4 to 6 , we find evidence consistent with this conjecture, as indicated by the statistically significant coefficients on the triple interaction terms. The results are economically large, as a onestandard-deviation increase in the HHI reduces the likelihood of closure following a class action ZIP code $\times$ six-digit NAICS industry $\times$ Month FEs leaves no variation in the treatment variable within a lawsuit, ZIP code, six-digit NAICS industry, and month. The fact that we cannot estimate the effect of having no competitor in the same lawsuit, ZIP code, six-digit NAICS industry, and month is also the reason why we find a positive and significant coefficient on the two-way interaction between the Treatment dummy and the Post dummy in Column 8. Technically, this coefficient captures the baseline effect of having no competitor, but since this effect cannot be estimated econometrically, the coefficient estimate is misspecified. 
lawsuit by $25 \%$. Taken together, the results from looking at the number of unique store visitors and store closures suggests that our results are robust to using alternative measures for customers' response to corporate misbehavior.

If a reputational effect is indeed responsible for the reduction in customer visits, we would expect stronger effects if the filing of the class action lawsuit, and thus potential corporate misbehavior, is more salient. This assumption is justified given that households overweigh stocks of firms located in close proximity (Grinblatt and Keloharju, 2001), exploit information on local firms in their favor (Ivković and Weisbrenner, 2005), and reduce stock holdings following corporate scandals at local firms (Giannetti and Wang, 2016). To test this conjecture, we augment the specification employed in Column 1 of Table 3 with an additional triple interaction term between the Treatment dummy, Post dummy, and the distance to corporate headquarters ${ }^{16}$ The results are reported in Column 1 of Table 5. The coefficient on the triple interaction term is positive and significant. This is consistent with our conjecture and implies that reputational effects have a spatial dimension in that reputation effects are more pronounced for outlets located closer to the firm's headquarters.

Certain customers may be more willing to punish firms for wrongdoing because of social norms. We test this conjecture by interacting the Treatment dummy and the Post dummy with county demographic characteristics that are likely to be correlated with customers' willingness to punish firms for wrongdoing, controlling for the impact of competition. As a first proxy for customers' willingness to punish firms for wrongdoing, we study religiousness in an outlet's county. Prior literature shows that religion affects various economic outcomes, including risk aversion (Noussair, Trautmann, van de Kuilen, and Vellekoop, 2013), stock market participation (Hong, Kubik, and Stein, 2004), the propensity to gamble (Kumar, Page, and Spalt, 2011), and firm behavior (Hilary and Hui, 2009). Results in Column 2 of Table 5 suggest that, controlling for the level of competition, the adverse reputational effect of corporate misbehavior is larger in areas with a more religious population. This finding implies that religiousness leads customers to hold firms accountable to higher moral standards. Next, we consider the percentage of Protestant and Catholic adherents, the two largest religious groups in the U.S., separately. The results are reported in Column 3. We document that Protestants (Catholics) are more (less) likely to hold firms accountable for

\footnotetext{
${ }^{16}$ For an overview of the spatial distribution of the locations of the firm's headquarters and the locations of the outlets, see Figure A.1
} 
misbehavior. This finding is consistent with Hasan, Noth, and Tonzer (2020), who argue that Protestants are less forgiving than Catholics and exert stricter monitoring of others' (mis)conduct.

As another proxy for customers' willingness to punish firms for wrongdoing, we study counties' social norms, as measured by the social capital index of Lin and Pursiainen (2020) ${ }^{17}$ The results are reported in Column 4. We find that stores located in counties with stronger social norms experience a stronger reduction in customer visits. This finding is in line with existing research arguing that high social capital imposes behavioral norms on managers (Hasan et al. 2017; Hoi et al. 2019) as well as communities more generally (e.g., Buonanno, Montolio, and Vanin, 2009), driven by a higher willingness to punish those who do not live by the norms of the community (e.g., Bowles and Gintis, 2002).

As a final proxy for customers' willingness to punish firms for wrongdoing, we consider counties' political orientation, as measured by the Republican vote share in the 2016 Presidential election. Results in Column 5 show that stores located in counties that lean towards the Republican party are more likely to be punished for wrongdoing. This result is consistent with the notion that the Republican ideology favors individual accountability and market discipline to punish corporate wrongdoing, while Democrats believe in government intervention to manage corporate crime (e.g., Hutton, Jiang, and Kumar, 2015).

Taken together, the results in this section provide outlet-level evidence that customers punish firms for corporate wrongdoing. This effect is strongly dependent on competition. Outlets facing more competition experience significantly larger negative effects. Hence, the ability of customers to punish firms for their wrongdoing critically hinges on the availability of alternatives for customers. The effect of competition differs across geographic and industry proximity, with more narrowly defined competition mattering more. It also robust to using unique visitors or store closures, rather than visits, as the dependent variable. Moreover, the effect varies across demographic characteristics of counties in which the outlets are located and is more pronounced in counties with stronger social norms and values, as proxied with religion, social capital, and political orientation.

\footnotetext{
${ }^{17}$ The index is based on principal component analysis of counties' association density, regulated charitable organization density, and voter turnout rate, following the methodology of Rupasingha, Goetz, and Freshwater (2006) and similar to the index used, for instance, in Hasan, Hoi, Wu, and Zhang (2017) and Hoi, Wu, and Zhanga (2019).
} 


\section{Competition and stock market response to class action lawsuits}

In the previous section, we have shown - in a very granular outlet-level setting - that customer's ability to punish firms for misbehavior depends on the competitive environment. We would therefore expect competition to also be a main driver of the stock market response to filings of class action lawsuits. This section is dedicated to this conjecture. First, we describe the sample used in this analysis. Next, we analyze the response of retail customers to class action lawsuits. Third, we study the impact of competition on the shareholder value response to class action lawsuits.

\subsection{Descriptive statistics}

Figure 2 displays means and 90\% confidence intervals for daily abnormal returns from 15 trading days before to five trading days after the filing date of the class action lawsuits. The figure shows that average daily abnormal returns are significantly negative for most trading days during this 21-day long window. The most negative abnormal return $(-1.6 \%)$ can be observed on the day before the filing date. Economically meaningful negative abnormal returns also occur two to four days before the filing date, suggesting that the disclosure of material adverse information that potentially serves as the event that triggers the filing of a lawsuit is incorporated into stock prices already before the filing. These patterns are consistent with findings in Gande and Lewis (2009). Hence, for our analysis of the returns around the filing date, we follow Gande and Lewis (2009) and use an asymmetric twelve-day event window that covers ten trading days before the filing date, the filing date, and the trading day after the filing date.

Table 6 reports descriptive statistics for the announcement return sample. The sample of class action lawsuits underlying this analysis comprises 3,322 cases. A target in a class action lawsuit on average competes with around 100 other firms within the same six-digit NAICS industry in the quarter before the filing of the lawsuit. The average revenue-based HHI calculated at the six-digit NAICS industry level for the firms in this sample is 0.3. Twelve-day CARs, computed from ten days before to one day after the filing of a class action lawsuit, are highly negative, with a mean of $-9.9 \%$ and a median of $-3.8 \%$. Prior studies document similar, if not even more negative, stock price responses to filings of class action lawsuits. Gande and Lewis (2009), for instance, find an average 
response of $-14.5 \%$ over the same twelve-day window using a sample of lawsuits filed between 1996 and 2003.

\section{$5.2 \quad$ Results}

To test whether the stock market response to filings of class action lawsuits are related to the competitive environment of firms targeted by the lawsuits, we regress the twelve-day CARs on five alternative measures of competition. For each competition measure, we first estimate a univariate regression and then rerun the regression augmented with a set of covariates capturing lawsuit and firm characteristics as well as year fixed effects. 18

The results are reported in Table7. As our first measure of competition, we use a revenue-based HHI computed at the six-digit NAICS level. Results in Column 1 show that firms active in a less competitive market have significantly higher (i.e., less negative) abnormal returns around the filing of a class action lawsuit. Specifically, an increase in the HHI by one standard deviation results in one percentage point lower cumulative abnormal returns. Results reported in Column 2 suggest that adding control variables leaves the coefficient and significance level almost unchanged. As a second measure of competition, we use the number of other firms active in the same six-digit NAICS industry. The results are reported in Columns 3 and 4 and show that the more competition a targeted firm faces, the more negative the market reacts to the filing of a class action lawsuit.19 The third measure of competition is a dummy variable that is equal to one for firms without any competitor in the six-digit NAICS industry, implying monopolistic market power. Results in Columns 5 and 6 show a positive and significant coefficient on the dummy variable indicating no competition. The coefficient estimates suggest that returns around filings of class action lawsuits are $4.8 \%$ or $4.2 \%$ higher (i.e., less negative, as the constant is $-10.0 \%$ and $-8.8 \%$, respectively) for firms without a competitor. As a fourth measure of competition, we employ a revenue-based HHI which relies on product descriptions in firms' annual reports to generate text-based industry classifications (Hoberg and Phillips, 2010, 2016). The results are reported in Columns 7 and 8 and show that both coefficient estimates on the TNIC-based HHI are insignificant, possibly because the TNIC industry

\footnotetext{
${ }^{18}$ Table A.3 presents the number of filings by calendar year and month.

${ }^{19}$ The coefficient on the number of competing firms remains negative and significant if we do a log-transformation of this variable.
} 
classification is too broad to capture competition at the product level. As our final measure of competition, we employ Hoberg and Phillips' firm-level measure of product market power, derived from pairwise similarity scores based on product descriptions in annual reports, with higher values indicating a higher product similarity - and thus easier substitutability - of a product with a competitor's product. Results are reported in Columns 9 and 10. The coefficients on the product similarity measure are negative and significant at the $1 \%$ level in both specifications, implying that firms whose customers can more easily substitute products with competitors' products experience more negative returns around the filing of a lawsuit.

The control variables added to the specifications reported in the even columns obtain loadings as expected from prior research. The dummy variable indicating whether class action lawsuit turns out to the be settled obtains a negative and highly significant coefficient. The coefficient estimate suggests that settled cases, on average, have $-7.2 \%$ lower returns around the filing date as do cases that will be dismissed. This suggests that investors are able to gauge the merit of lawsuits at the filing date (Griffin, Grundfest, and Perino, 2004, Kempf and Spalt, 2020). Firms with higher market-to-book ratios, a proxy for growth opportunities, and firms with less property plant and equipment as a fraction of total assets, a proxy for the asset intensity, also have significantly more negative abnormal returns. This is consistent with a growing literature showing that firms with valuable innovation output are particularly vulnerable to class action litigation (Lin et al., 2020 , Kempf and Spalt, 2020).

Results in this section show that competition in firms' product markets is a key determinant of the stock market response to filings of class action lawsuits. Hence, the results in this section support our previous results from the outlet-level analysis, suggesting that competition is an important component in customers' ability to discipline firms for misbehavior. Moreover, these results imply that shareholders are well-aware of the benefits of a concentrated market structure in impeding customers' ability to discipline a firm when a class action lawsuit is filed.

\section{Competition and revenue response to class action lawsuits}

Our analysis in Section 4, based on very granular outlet-level data, is restricted to 29 class action lawsuits filed after February 2018. To confirm that our results on customer visits are not confined to 
the sample of class action lawsuits that overlaps with the SafeGraph data, we perform an analysis of quarterly accounting revenues using a comprehensive sample of class action lawsuits filed since 1996. In this section, we first describe the sample used in this analysis. Next, we analyze the change in quarterly accounting revenues, our proxy for customers' response, around filings of class action lawsuits. Third, we study the impact of competition on changes in revenues. Finally, we test whether reductions in revenue are more severe for lawsuits that are likely to contain more drastic accusations of corporate misbehavior and lawsuits that are likely to have more merit.

\subsection{Descriptive statistics}

Table 8 reports descriptive statistics for the quarterly firm panel. The sample of class action lawsuits underlying this analysis comprises 3,582 cases filed since 1996 20 On average, a firm has quarterly revenue of 223 million USD and competes with around 233 other firms within its six-digit NAICS industry. The average revenue-based HHI calculated at the six-digit NAICS industry level for the firms in this sample is 0.16 .

\subsection{Results}

To analyze the customers' response to class action lawsuits, we estimate the change in accounting revenue of firms targeted by a class action lawsuit from four quarters before to eight quarters after the filing quarter and compare it to changes in revenues of firms in the same quarter. Similar to the analysis in Section 4 , we first conduct a quarterly regression analysis specified as:

$$
\ln \left(\text { Revenue }_{i, s, t}=\beta_{t} \times \text { Treatment }_{i, s} \times \text { Event quarter }_{i, t}+\alpha_{i, s}+\alpha_{s, t, j}+\epsilon_{i, s, t},\right.
$$

where $i$ indexes a firm, $s$ a lawsuit, $t$ a quarter, and $j$ an industry. Revenue is the quarterly revenue. Treatment is a dummy indicating whether the firm is the target of a lawsuit. Event quarter are dummies indicating quarters relative to the filing quarter. We include interacted lawsuit and firm fixed effects as well as interacted lawsuit, month, and industry fixed effects, which absorb all timeinvariant firm characteristics within a lawsuit, including the Treatment dummy.

\footnotetext{
${ }^{20}$ The sample of class action lawsuits used in this analysis is larger than the one used for the announcement return analysis because of stock market availability from the CRSP. Moreover, at the time of writing, CRSP return data is only available until December 31, 2019, while Compustat data is available through 2020.
} 
Figure 3 shows the estimated quarterly regression coefficients for the interacted treatmentquarter dummies, relative to the quarter preceeding the filing of the lawsuit (omitted in the regression). Similar to the outlet-level results reported in Section 4 revenue for firms targeted in class action lawsuits starts falling before the announcement. The revenue decline at the firm level seems to be somewhat larger in magnitude and lasts longer than the declined in store visits estimated at the outlet level. This may be due to the larger sample or due to other factors like store closures or divestments, that are not captured by outlet visits, having an additional negative effect on firm-level revenue.

Again, to facilitate further cross-sectional analysis of heterogeneity in the reputation effect across treated stores, we define an indicator variable that equals one for the filing quarter and the three quarters after (Post) and perform an interaction term of this dummy with the Treatment dummy. This analysis is specified as:

$$
\ln (\text { Revenue })_{i, s, t}=\beta_{1} \times \text { Treatment }_{i, s} \times \text { Post }_{i, t}+\beta_{2} \times \text { Post }_{i, t}+\alpha_{i, s}+\epsilon_{i, s, t} .
$$

The results are reported in Table 9. In Column 1, the coefficient on the interaction term shows that firms targeted by a class action lawsuit experience a reduction in revenue of $-10 \%$ in the filing quarter and the three quarters following the filing quarter of the lawsuit. In Column 2, we add interacted industry and quarter fixed effects. In Column 3, we add interacted lawsuit, industry, and quarter fixed effects and in Column 4, we augment our model with interacted lawsuit, industry, quarter, and state fixed effects. The interacted fixed effects in the last specification, i.e., in Column 4, ensure that we compare changes in revenue of treated firms with changes in revenue of firms in the same industry and quarter that are headquartered in the same state. Therefore, these fixed effects control for a range of characteristics, including the time trend, industry shocks that coincide with the filing, and time-varying headquarter-state characteristics. Taken together, these results on accounting revenues provide strong evidence of reputational costs of class action lawsuits and suggest that the results documented in the outlet-level analysis are not confined to the sample used in that analysis.

Next, we test whether the drop in revenue around filings of class action lawsuits depends on competition. To this end, we augment our analysis with a triple interaction term, which interacts 
the existing interaction term between the Treatment dummy and the Post dummy with five different measures of competition similar to those used in Section 5 above. These additional interaction terms allow us to gauge the incremental impact of customers' ability to substitute the products of a firm targeted in a class action lawsuit with products of competing firms.

The results are reported in Table 10. The coefficient on the triple interaction term shows the expected sign across all five specifications and is statistically significant in four specifications. As in the outlet-level analysis, the economic magnitude of these results is sizeable. For instance, an increase in competition, as measured by the HHI calculated within the same six-digit NAICS industry, by one standard deviation is associated with a two-percentage-point loss of revenue. Hence, these findings further suggest that competition is an important component in customers' ability to discipline firms for misbehavior.

In our next analysis, we test whether reductions in revenue are more severe for lawsuits that are likely to contain more drastic accusations of corporate misbehavior and lawsuits that are likely to have more merit. To this end, we interact the existing interaction term between the Treatment dummy and Post dummy with either the twelve-day CARs around the lawsuit's filing date or a dummy variable whether a lawsuit is settled (rather than dismissed).

Table 11 reports the results. In Column 1, we find that more negative abnormal returns around the filing of the lawsuit are associated with larger reductions in revenue. This finding shows that more negative stock market responses are associated with larger revenue losses, which is consistent with the conjecture that cases where customers believe that a boycott seems more appropriate due to more severe allegations trigger larger reputation effects, which are correctly anticipated by the market. Similarly, in Column 2, we find that settled lawsuits are associated with a stronger reduction in revenue, implying that lawsuits that have more merit are associated with stronger reductions in revenue around the filing. These results suggest that reductions in revenue are more severe for lawsuits that are likely to contain more drastic accusations of corporate misbehavior and lawsuits that are likely to have more merit.

Taken together, the results in this section show that our results on customer visits are not confined to the sample of class action lawsuits that overlaps with the SafeGraph data but generalize to a comprehensive sample of about 3,800 class action lawsuits filed between 1996 and 2020. Hence, 
our results obtained using different methodologies and across different samples provide strong and consistent evidence of the importance of competition on the ability of customers to discipline firms for misbehavior.

\section{Additional analysis}

\subsection{Media attention around class action lawsuits}

Our results suggest that retail customers reduce their visits in the outlets of firms targeted in class action lawsuits. In order for them to do so, they need to be aware of either the lawsuit or the misconduct that led to the lawsuit. One obvious channel through which retail customers may obtain information is the media. To test whether media attention on firms increases around class action lawsuits, we collect data on the monthly number of news articles for each firm in our outlet sample targeted by a lawsuit, using the Factiva news database. We then perform a regression analysis of the number of articles about the firm around the filing month.

Figure 4 plots the monthly regression coefficients, relative to five calendar months before the month of the filing of the lawsuit. Media attention increases substantially (nearly doubles on average) for approximately three months, from the month before the class action announcement until one month after the announcement and then decreases to levels similar to or below the months preceding the lawsuit. This suggests that the misconduct and the lawsuit itself attract attention in the media and likely make the events more salient for retail customers.

\subsection{Retail trader response to class action lawsuits}

Another complementary channel through which retail customers might learn of lawsuits or the events leading up to them are stock investments. Retail investestors have additional incentives to monitor the companies they own or consider investing in. Keloharju et al. (2012) find that retail investors' investment decisions are influenced by their product market choices. Hence, it is likely

that many investors in a retail company stock are also its customers. If retail investors learn of a lawsuit or the misconduct that caused it, they may react both as consumers as well as investors. Consistently, the results of Giannetti and Wang (2016) suggest that retail investors recognize and 
respond to corporate misconduct. Furthermore, retail investors may propagate the information through their social connections, amplifying the consumer reaction.

To study retail investors' reactions to class action lawsuits, we use retail trading data from Robinhood. Robinhood is a large brokerage platform that targets small and cost-conscious retail investors with its no-brokerage-fees business model. It earns its revenue primarily through margin fees, cash balance interest, and payment-for-order flow. For the period from May 2018 to August 2020, Robinhood offered an Application Programming Interface (API) that provided the number of accounts holding each stock. These data were systematically collected by a website called Robintrack.net, which offers a dataset comprising the number of accounts holding each stock on an hourly basis. This dataset has been used in a number of studies of retail investor behavior (e.g., Barber, Huang, Odean, and Schwarz, 2021; Welch, 2020, Pagano, Sedunov, and Velthuis, 2021). We use these data to construct a daily panel dataset of retail accounts holding the stock of each firm that is the target of a lawsuit in our outlet sample. We construct the control sample by matching all firms in the same six-digit NAICS industry as the firms targeted by the lawsuits. We then perform a regression analysis in which we compare the change in the number of retail accounts holding stocks of firms targeted by the lawsuits around the filing date with the change in the number of retail accounts holding stocks of control firms.

Panel A of Figure 5 plots the daily regression coefficients, relative to two trading days before the filing of the class action lawsuit. We find a statistically significant reduction in the number of retail accounts holding stocks of firms targeted around the filing date compared to firms in the same industry, with approximately 10\% reduction in retail holders during the 15 days following the filing. Panel B of Figure 5 plots monthly regression coefficients for five months before to five months after the filing month of the lawsuit. These coefficient estimates imply that the downward trend continues over several months and does not revert, with the number of retail accounts holding the stocks of firms targeted in a lawsuit dropping to around $26 \%$ four months after the filing month. Taken together, the findings presented in this section suggests that it is reasonable to assume that retail customers are aware of the lawsuits, as media coverage increases substantially and retail traders respond by divesting stocks. 


\section{Conclusion}

The basis of a fair and functioning legal system is that everyone is subject to the same laws and risks similar penalties when breaking those laws. Our findings highlight a worrying aspect of the current system, where a substantial part of the damages suffered by firms from litigation come in the form of reputational losses. We show that such losses are meaningful only when there is adequate competition. This means that the firms with substantial market power may not be disciplined in the same way as firms with less market power. This is even more worrying given the evidence that markets and industries have generally grown more concentrated and less competitive over the last few decades. This might suggest that legal punitive damages need to increase with an increase in market power to maintain the intended deterrent effect. Our results on the differential effects of competition measured at different levels and granularities may also have important implications in other contexts. We show that competition measured at the micro level appears significantly more important than competition measured at a broader level, both in terms of geography and industry definitions. 


\section{References}

Admati, Anat R., and Paul Pfleiderer, 2009, The "Wall Street Walk" and shareholder activism: Exit as a form of voice, Review of Financial Studies 22, 2645-2685.

Aghion, Philippe, Nick Bloom, Richard Blundell, Rachel Griffith, and Peter Howitt, 2005, Competition and innovation: An inverted-U relationship, Quarterly Journal of Economics 120, 701-728.

Alexander, Cindy R., 1999, On the nature of the reputational penalty for corporate crime: Evidence, Journal of Law and Economics 42, 489-526.

Arena, Matteo, and Brandon Julio, 2015, The effects of securities class action litigation on corporate liquidity and investment policy, Journal of Financial and Quantitative Analysis 50, 251-275.

Ashenfelter, Orley, and Timothy Hannan, 1986, Sex discrimination and product market competition: The case of the banking industry, Quarterly Journal of Economics 101, 149-173.

Azar, José, Martin C. Schmalz, and Isabel Tecu, 2018, Anticompetitive effects of common ownership, Journal of Finance 73, 1513-1565.

Bae, Kee-Hong, Warren Bailey, and Jisok Kang, 2021, Why is stock market concentration bad for the economy?, Journal of Financial Economics 140, 436-459.

Barber, Brad M., Xing Huang, Terrance Odean, and Christopher Schwarz, 2021, Attention induced trading and returns: Evidence from Robinhood users, Working paper.

Bhagat, Sanjai, John Bizjak, and Jeffrey L. Coles, 1998, The shareholder wealth implications of corporate lawsuits, Financial Management 27, 5-27.

Bhagat, Sanjai, James A. Brickley, and Jeffrey L. Coles, 1994, The costs of inefficient bargaining and financial distress: Evidence from corporate lawsuits, Journal of Financial Economics 35, $221-247$.

Bharath, Sreedhar T., Sudarshan Jayaraman, and Venky Nagar, 2013, Exit as governance: An empirical analysis, Journal of Finance 86, 2515-2547. 
Bizjak, John M., and Jeffrey L. Coles, 1995, The effect of private antitrust litigation on the stockmarket valuation of the firm, American Economic Review 85, 436-461.

Bizjak, John M., Swaminathan L. Kalpathy, Vassil T. Mihov, and Jue Ren, 2020, CEO political leanings and store-level economic activity during COVID-19 crisis: Effects on shareholder value and public health, Working paper.

Borenstein, Severin, and Nancy L. Rose, 1994, Competition and price dispersion in the U.S. airline industry, Journal of Political Economy 102.

Bowles, Samuel, and Herbert Gintis, 2002, Social capital and community governance, Economic Journal 112, F491-F436.

Broccardo, Eleonora, Oliver Hart, and Luigi Zingales, 2020, Exit vs. voice, Working paper.

Brochet, Francois, and Suraj Srinivasan, 2014, Accountability of independent directors: Evidence from firms subject to securities litigation, Journal of Financial Economics 111, 430-449.

Brown, Jeffrey R., and Austan Goolsbee, 2002, Does the internet make markets more competitive? Evidence from the life insurance industry, Journal of Political Economy 110, 481-507.

Buonanno, Paolo, Daniel Montolio, and Paolo Vanin, 2009, Does social capital reduce crime?, Journal of Law and Economics 52, 145-170.

Carhart, Mark M., 1997, On persistence in mutual fund performance, Journal of Financial Economics 52, 57-82.

Charoenwong, Ben, Alan Kwan, and Vesa Pursiainen, 2020, Social connections with COVID19-affected areas increase compliance with mobility restrictions, Science Advances 6.

Chod, Jiri, and Evgeny Lyandres, 2011, Strategic IPOs and product market competition, Journal of Financial Economics 100, 45-67.

Covarrubias, Matias, Germán Gutiérrez, and Thomas Philippon, 2019, From good to bad concentration? U.S. industries over the past 30 years, Working paper. 
Dafny, Leemore, Mark Duggan, and Subramaniam Ramanarayanan, 2012, Paying a premium on your premium? Consolidation in the U.S. health insurance industry, American Economic Review $102,1161-85$.

De Loecker, Jan, and Jan Eeckhout, 2018, Global market power, Working paper.

Desai, Hemang, Chris E. Hogan, and Michael S. Wilkins, 2006, The reputational penalty for aggressive accounting: Earnings restatements and management turnover, Accounting Review 81, $83-112$.

Dyck, Alexander, Adair Morse, and Luigi Zingales, 2020, How pervasive is corporate fraud?, Working paper.

Edmans, Alex, 2014, Blockholders and corporate governance, Annual Review of Financial Economics $6,23-50$.

Fama, Eugene F., and Kenneth R. French, 1993, Common risk factors in the returns on stocks and bonds, Journal of Financial Economics 33, 3-56.

Fich, Eliezer M., and Anil Shivdasani, 2007, Financial fraud, director reputation, and shareholder wealth, Journal of Financial Economics 86, 306-336.

Gande, Amar, and Craig M. Lewis, 2009, Shareholder-initiated class action lawsuits: Shareholder wealth effects and industry spillovers, Journal of Financial and Quantitative Analysis 44, 823850.

Gaspar, José-Miguel, and Massimo Massa, 2006, Idiosyncratic volatility and product market competition, Journal of Business 79, 3125-3152.

Giannetti, Mariassunta, and Tracy Yue Wang, 2016, Corporate scandals and household stock market participation, Journal of Finance 71, 2591-2636.

Giroud, Xavier, and Holger M. Mueller, 2010, Does corporate governance matter in competitive industries?, Journal of Financial Economics 95, 312-331.

Giroud, Xavier, and Holger M. Mueller, 2011, Corporate governance, product market competition, and equity prices, Journal of Finance 66, 563-600. 
Griffin, Paul A., Joseph A. Grundfest, and Michael A. Perino, 2004, Stock price response to news of securities fraud litigation: An analysis of sequential and conditional information, Abacus 40, $21-48$.

Grinblatt, Mark, and Matti Keloharju, 2001, How distance, language, and culture influence stockholdings and trades, Journal of Finance 56, 1053-1073.

Grullon, Gustavo, Yelena Larkin, and Roni Michaely, 2019, Are US industries becoming more concentrated?, Review of Finance 23, 697-743.

Gurun, Umit, Jordan Nickerson, and David H. Solomon, 2020, The perils of private provision of public goods, Working paper.

Hart, Oliver D., 1983, The market mechanism as an incentive scheme, Bell Journal of Economics $14,366-382$.

Hasan, Iftekhar, Chun-Keung Hoi, Qiang Wu, and Hao Zhang, 2017, Does social capital matter in corporate decisions? Evidence from corporate tax avoidance, Journal of Accounting Research $55,629-668$.

Hasan, Iftekhar, Felix Noth, and Lena Tonzer, 2020, Thou shalt not bear false witness against your customers: Cultural norms and the Volkswagen scandal, Working paper.

Helland, Eric, 2006, Reputational penalties and the merits of class-action securities litigation, Journal of Law and Economics 49, 365-395.

Hilary, Gilles, and Kai Wai Hui, 2009, Does religion matter in corporate decision making in America?, Journal of Financial Economics 93, 455-473.

Hoberg, Gerard, and Gordon Phillips, 2010, Product market synergies and competition in mergers and acquisitions: A text-based analysis, Review of Financial Studies 23, 3773-3811.

Hoberg, Gerard, and Gordon Phillips, 2016, Text-based network industries and endogenous product differentiation, Journal of Political Economy 124, 1423-1465. 
Hoi, Chun Keung, Qiang Wu, and Hao Zhanga, 2019, Does social capital mitigate agency problems? Evidence from Chief Executive Officer (CEO) compensation, Journal of Financial Economics $133,498-519$.

Homanen, Mikael, 2018, Depositors disciplining banks: The impact of scandals, Working paper.

Hong, Harrison, Jeffrey D. Kubik, and Jeremy C. Stein, 2004, Social interaction and stock-market participation, Journal of Finance 59, 137-163.

Hou, Kewei, and David T. Robinson, 2006, Industry concentration and average stock returns, Journal of Finance 61, 1927-1956.

Hutton, Irena, Danling Jiang, and Alok Kumar, 2015, Political values, culture, and corporate litigation, Management Science 61, 2905-2925.

Irvine, Paul J., and Jeffrey Pontiff, 2009, Idiosyncratic return volatility, cash flows, and product market competition, Review of Financial Studies 22, 1149-1177.

Ivković, Zoran, and Scott Weisbrenner, 2005, Local does as local is: Information content of the geography of individual investors common stock investments, Journal of Finance 60, 267-306.

Johnson, William C., Wenjuan Xie, and Sangho Yi, 2014, Corporate fraud and the value of reputations in the product market, Journal of Corporate Finance 25, 16-39.

Jung, Hae Won (Henny), and Ajay Subramanian, 2017, CEO talent, CEO compensation, and product market competition, Journal of Financial Economics 125, 48-71.

Kahle, Kathleen M., and René M. Stulz, 2017, Is the US public corporation in trouble?, Journal of Economic Perspectives 31, 67-88.

Karpoff, Jonathan M., 2012, The Oxford Handbook of Corporate Reputation, chapter Does Reputation Work to Discipline Corporate misconduct? (Oxford University Press).

Karpoff, Jonathan M., D. Scott Lee, and Gerald S. Martin, 2008, The consequences to managers for financial misrepresentation, Journal of Financial Economics 88, 193-215.

Karpoff, Jonathan M., and John R. Lott, 1993, The reputational penalty firms bear from committing criminal fraud, Journal of Law and Economics 36, 757-802. 
Karpoff, Jonathan M., and John R. Lott, 1999, On the determinants and importance of punitive damage awards, Journal of Law and Economics 42, 527-573.

Keloharju, Matti, Samuli Knüpfer, and Juhani Linnainmaa, 2012, Do investors buy what they know? product market choices and investment decisions, Review of Financial Studies 25, 29212958.

Kempf, Elisabeth, and Oliver G. Spalt, 2020, Attracting the sharks: Corporate innovation and securities class action lawsuits, Working paper.

Kim, E. Han, and Vijay Singal, 1994, Mergers and market power: Evidence from the airline industry, American Economic Review 83, 549-569.

Kumar, Alok, Jeremy K. Page, and Oliver G. Spalt, 2011, Religious beliefs, gambling attitudes, and financial market outcomes, Journal of Financial Economics 102, 671-708.

Lin, Chen, Sibo Liu, and Gustavo Manso, 2020, Shareholder litigation and corporate innovation, Management Science forthcoming.

Lin, Tse-Chun, and Vesa Pursiainen, 2020, Fund what you trust? Social capital in crowdfunding, Working paper.

Matsa, David A., 2011, Competition and product quality in the supermarket industry, Quarterly Journal of Economics 126, 1539-1591.

Murphy, Deborah L., Ronald E. Shrieves, and Samuel L. Tibbs, 2009, Understanding the penalties associated with corporate misconduct: An empirical examination of earnings and risk, Journal of Financial and Quantitative Analysis 44, 55-83.

Nickell, Stephen J., 1996, Competition and corporate performance, Journal of Political Economy $104,724-746$.

Noussair, Charles N., Stefan T. Trautmann, Gijs van de Kuilen, and Nathanael Vellekoop, 2013, Risk aversion and religion, Journal of Risk and Uncertainty 47, 165-183. 
Pagano, Michael S., John Sedunov, and Raisa Velthuis, 2021, How did retail investors respond to the COVID-19 pandemic? The effect of Robinhood brokerage customers on market quality, Finance Research Letters forthcoming.

Painter, Marcus, 2020, Consumer response to corporate political statements: Evidence from geolocation data, Working paper.

Raith, Michael, 2003, Competition, risk, and managerial incentives, American Economic Review 93, 1425-1436.

Rupasingha, Anil, Stephan J. Goetz, and David Freshwater, 2006, The production of social capital in US counties, Journal of Socio-Economics 35, 83-101.

Shapiro, Carl, 2019, Protecting competition in the American economy: Merger control, tech titans, labor markets, Journal of Economic Perspectives 33, 69-93.

Tirole, Jean, 1988, The Theory of Industrial Organization (MIT Press, Cambridge, MA).

Valta, Philip, 2012, Competition and the cost of debt, Journal of Financial Economics 105, 661682.

Weill, Joakim A., Matthieu Stigler, Olivier Deschenes, and Michael R. Springborn, 2020, Social distancing responses to COVID-19 emergency declarations strongly differentiated by income, Proceedings of the National Academy of Sciences 117, 19658-19660.

Welch, Ivo, 2020, The wisdom of the Robinhood crowd, Working paper. 
Appendix A: Variable definitions

This table reports variable definitions of all variables used in the paper as well as their data sources. Database mnemonics are in italics (if available).

\begin{tabular}{|c|c|c|}
\hline Variable & Definition & Source \\
\hline Visits & Number of visits of an outlet in a calendar month. & SafeGraph \\
\hline Visitors & Number of distinct visitors of an outlet in a calendar month. & SafeGraph \\
\hline Closed & $\begin{array}{l}\text { Dummy variable set equal to one if a store disappears from the sample in the next month, zero } \\
\text { otherwise. }\end{array}$ & SafeGraph \\
\hline HHI ZIP NAICS6 & $\begin{array}{l}\text { Herfindahl-Hirschman index, calculated as the sum of squared market shares of all firms in the } \\
\text { filing year, ZIP code, and six-digit NAICS industry. A firm's market share is computed using } \\
\text { the fraction of outlets. }\end{array}$ & SafeGraph \\
\hline HHI ZIP NAICS4 & $\begin{array}{l}\text { Herfindahl-Hirschman index, calculated as the sum of squared market shares of all firms in the } \\
\text { filing year, ZIP code, and four-digit NAICS industry. A firm's market share is computed using } \\
\text { the fraction of outlets. }\end{array}$ & SafeGraph \\
\hline HHI ZIP NAICS2 & $\begin{array}{l}\text { Herfindahl-Hirschman index, calculated as the sum of squared market shares of all firms in the } \\
\text { filing year, ZIP code, and two-digit NAICS industry. A firm's market share is computed using } \\
\text { the fraction of outlets. }\end{array}$ & SafeGraph \\
\hline HHI County NAICS6 & $\begin{array}{l}\text { Herfindahl-Hirschman index, calculated as the sum of squared market shares of all firms in the } \\
\text { filing year, county, and six-digit NAICS industry. A firm's market share is computed using the } \\
\text { fraction of outlets. }\end{array}$ & SafeGraph \\
\hline HHI State NAICS6 & $\begin{array}{l}\text { Herfindahl-Hirschman index, calculated as the sum of squared market shares of all firms in the } \\
\text { filing year, state, and six-digit NAICS industry. A firm's market share is computed using the } \\
\text { fraction of outlets. }\end{array}$ & SafeGraph \\
\hline \# other brand & $\begin{array}{l}\text { Number of other firms with an outlet active in the same six-digit NAICS industry, ZIP code, } \\
\text { and filing year. }\end{array}$ & SafeGraph \\
\hline One competing brand & Dummy variable set equal to one if \# other brands equals one, zero otherwise. & SafeGraph \\
\hline Distance to HQ & $\begin{array}{l}\text { Distance (in kilometers) of an outlet to the headquarter of the firm that is the target of a class } \\
\text { action lawsuit. }\end{array}$ & $\begin{array}{l}\text { SafeGraph, Compustat, web } \\
\text { searches }\end{array}$ \\
\hline Religious (\%) & Adherents per capita in a county (totrate). & 2010 U.S. Religion Census \\
\hline Protestants $(\%)$ & Protestant adherents per capita in a county (evanrate + bprtrate + mprtrate $)$. & 2010 U.S. Religion Census \\
\hline Catholics (\%) & Catholic adherents per capita in a county (cathrate). & 2010 U.S. Religion Census \\
\hline Social capital & $\begin{array}{l}\text { County-level principal component analysis of association density, regulated charitable organi- } \\
\text { zation density, and voter turnout rate. }\end{array}$ & Lin and Pursiainen (2020) \\
\hline Republican (\%) & Fraction of votes obtained by Republic Party in 2016 Presidential Election in a county. & $\begin{array}{l}\text { MIT Election Data and Science } \\
\text { Lab }\end{array}$ \\
\hline CAR $(-10,1)$ & $\begin{array}{l}\text { Cumulative abnormal return, estimated as the sum of daily (unwinsorized) abnormal returns } \\
\text { from ten trading days before the event date to one trading day after the event date where } \\
\text { the filing date of a security class action lawsuit marks the event date. Daily abnormal returns } \\
\text { are calculated as the observed return (ret) minus a predicted return. The predicted return } \\
\text { is estimated using a market model regression where daily returns (ret) are regressed on daily } \\
\text { value-weighted index returns (vwret) over a } 250 \text {-day estimation window that ends eleven trading } \\
\text { days prior to the event date. At least } 90 \text { daily observations with non-missing stock return data } \\
\text { are required. Winsorized at the } 1^{\text {st }} \text { and } 99^{\text {th }} \text { percentiles. }\end{array}$ & CRSP \\
\hline
\end{tabular}




\section{HHI NAICS6}

\# other firms

No competing firm

One competing firm

\section{HHI HP}

Product similarity HP Settled

Market cap.

\section{Leverage}

ROE

MTB

$\mathrm{PPE} / \mathrm{AT}$

Foreign revenue (\%)

Idiosyncratic vola

Revenue

\# newspaper articles

\# Robinhood accounts

Herfindahl-Hirschman index, calculated as the sum of squared market shares of all firms in the Compustat quarterly same fiscal quarter and six-digit NAICS industry. A firm's market share is computed using revenue $($ revtq).

Number of other firms in the same fiscal quarter in the same six-digit NAICS industry.

Dummy variable set equal to one if \# other firms equals zero, zero otherwise.

Compustat quarterly Compustat quarterly

Dummy variable set equal to one if \# other firms equals one, zero otherwise.

Compustat quarterly

Herfindahl-Hirschman index, calculated as the sum of squared market shares of all firms in the Hoberg-Phillips Data Library

same fiscal year and TNIC industry. A firm's market share is computed using revenue (revt).

Product similiarity score for the firm's fiscal year.

Dummy variable set equal to one if a class action lawsuit is settled, zero otherwise.

Hoberg-Phillips Data Library Stanford's Securities Class

Action Clearinghouse

Market capitalization $(\operatorname{prc} \times($ shrout $\times 1,000))$ eleven trading days prior to the filing of the CRSP class action lawsuit.

Long-term debt (revtq) and debt in current liabilities $(d l c q)$ scaled by total assets $(a t q)$.

Net income (niq) scaled by book value equity $(c e q q)$.

Market capitalization $(\operatorname{prccq} \times c s h o q)$ scaled by book value equity $(c e q q)$.

Propertly plant and equipment (ppentq) scaled by total assets (atq).

Compustat quarterly

Compustat quarterly

Compustat quarterly

Compustat quarterly

Sum of foreign revenue across all segments (salexg) scaled by revenue in a financial year (revt). Compustat segments

Compustat annual

Root mean squared error of market model regression.

CRSP

Amihud's illiquidity measure estimated during the estimation window.

Revenue $(r e v t q)$ in the quarter where a securities class action lawsuit is filled.

Number of articles covering a firm.

Number of different accounts holding the stock.
CRSP

Compustat quarterly

Factiva

Robintrack.net 
Table 1

Descriptive statistics - monthly outlet sample

This table presents descriptive statistics for the outlet-month panel. The sample of treated outlets comprises 25,155 outlets associated with a firm involved in a class action lawsuit. From the Securities Class Action Clearinghouse database, we drop lawsuits involving financial firms (two-digit NAICS industry 52), lawsuits targeting firms headquartered outside of the U.S., lawsuits filed before March 1, 2018, lawsuits filed after February 29, 2020, and lawsuits for which we cannot match outlets in SafeGraph. We also drop outlets for which we cannot match control outlets. For each treated outlet, we retain eleven monthly observations around the filing month of a lawsuit, five months before and five months after. The control sample is constructed by selecting all monthly observations of outlets in the same ZIP code and six-digit NAICS industry as the treated outlets. Detailed descriptions of all variables used throughout the study are provided in the Appendix.

\begin{tabular}{lccccc}
\hline & Mean & Std & $\mathrm{p} 25$ & $\mathrm{p} 50$ & $\mathrm{p} 75$ \\
\hline Store outcomes & & & & & \\
Visits & 405.247 & 707.815 & 103.000 & 260.000 & 494.000 \\
Visitors & 273.594 & 372.261 & 72.000 & 184.000 & 350.000 \\
Closed × 100 & 0.108 & 3.291 & 0.000 & 0.000 & 0.000 \\
Treatment & 0.137 & 0.344 & 0.000 & 0.000 & 0.000 \\
Competition & & & & & \\
HHI ZIP NAICS6 & 0.141 & 0.131 & 0.055 & 0.077 & 0.194 \\
HHI ZIP NAICS4 & 0.104 & 0.116 & 0.032 & 0.050 & 0.133 \\
HHI ZIP NAICS2 & 0.068 & 0.083 & 0.025 & 0.037 & 0.063 \\
HHI County NAICS6 & 0.112 & 0.111 & 0.045 & 0.059 & 0.148 \\
HHI State NAICS6 & 0.105 & 0.114 & 0.049 & 0.058 & 0.061 \\
\# other brands & 13.453 & 9.158 & 4.000 & 14.000 & 20.000 \\
One competing brand & 0.106 & 0.308 & 0.000 & 0.000 & 0.000 \\
Store characteristics & & & & & \\
Distance to HQ & 1248.520 & 959.631 & 528.553 & 1008.397 & 1707.724 \\
Religious (\%) & 0.551 & 0.135 & 0.451 & 0.545 & 0.642 \\
Protestants (\%) & 0.343 & 0.183 & 0.180 & 0.326 & 0.475 \\
Catholics (\%) & 0.158 & 0.114 & 0.067 & 0.136 & 0.219 \\
Social capital & -0.695 & 0.651 & -1.153 & -0.656 & -0.255 \\
Republican (\%) & 0.477 & 0.163 & 0.366 & 0.469 & 0.596 \\
\hline N & $2,099,633$ & & & & \\
\hline
\end{tabular}




\section{Table 2}

\section{Retail customer response to class action lawsuits}

This table presents results of ordinary least squares regressions using the logarithm of the number of monthly outlet visits as the dependent variable. Treatment is a dummy variable set equal to one if an outlet belongs to a firm that is the target in a class action lawsuit, zero otherwise. Post is a dummy variable set equal to one for the month of the filing of the class action lawsuit and all months thereafter. The sample of treated outlets comprises 25,155 outlets associated with a firm involved in a class action lawsuit. From the Securities Class Action Clearinghouse database, we drop lawsuits involving financial firms (two-digit NAICS industry 52), lawsuits targeting firms headquartered outside of the U.S., lawsuits filed before March 1, 2018, lawsuits filed after February 29, 2020, and lawsuits for which we cannot match outlets in SafeGraph. For each treated outlet, we retain eleven monthly observations around the filing month of a lawsuit, five months before and five months after. The control sample is constructed by selecting all monthly observations of outlets in the same ZIP code and six-digit NAICS industry as the treated outlets. Detailed descriptions of all variables used throughout the study are provided in the Appendix. Standard errors, reported in parentheses, are clustered at the firm - month level. ${ }^{* * *},{ }^{* *},{ }^{*}$ denote statistical significance at the $1 \%, 5 \%$, and $10 \%$ level, respectively.

\begin{tabular}{lccc}
\hline & \multicolumn{3}{c}{$\ln ($ Visits $)$} \\
\cline { 2 - 4 } & $(1)$ & $(2)$ & $(3)$ \\
\hline Treatment $\times$ Post & $-0.0536^{* * *}$ & $-0.0662^{* * *}$ & $-0.0377^{* * *}$ \\
Post & $(0.0153)$ & $(0.0104)$ & $(0.0109)$ \\
& $0.1114^{* * *}$ & $0.0180^{* * *}$ & \\
Lawsuit x Outlet FE & $(0.0041)$ & $(0.0048)$ & Yes \\
Month FE & Yes & Yes & No \\
Lawsuit x ZIP x NAICS x Month FE & No & Yes & Yes \\
\hline $\mathrm{N}$ & No & No & $2,099,633$ \\
$R^{2}$ & $2,099,633$ & $2,099,633$ & 0.977 \\
\hline
\end{tabular}


Table 3

\section{Competition and retail customer response to class action lawsuits}

This table presents results of ordinary least squares regressions using the logarithm of the monthly number of outlet visits as the dependent variable. Treatment is a dummy variable set equal to one if an outlet belongs to a firm that is the target in a class action lawsuit, zero otherwise. Post is a dummy variable set equal to one for the month of the filing of the class action lawsuit and all months thereafter. The sample of treated outlets comprises 25,155 outlets associated with a firm involved in a class action lawsuit. From the Securities Class Action Clearinghouse database, we drop lawsuits involving financial firms (two-digit NAICS industry 52), lawsuits targeting firms headquartered outside of the U.S., lawsuits filed before March 1, 2018, lawsuits filed after February 29, 2020, and lawsuits for which we cannot match outlets in SafeGraph. We also drop outlets for which we cannot match control outlets. For each treated outlet, we retain eleven monthly observations around the filing month of a lawsuit, five months before and five months after. The control sample is constructed by selecting all monthly observations of outlets in the same ZIP code and six-digit NAICS industry as the treated outlets. Detailed descriptions of all variables used throughout the study are provided in the Appendix. Standard errors, reported in parentheses, are clustered at the firm - month level. ***, **, * denote statistical significance at the $1 \%, 5 \%$, and $10 \%$ level, respectively.

\begin{tabular}{|c|c|c|c|c|c|c|c|c|c|}
\hline & \multicolumn{9}{|c|}{$\ln$ (Visits) } \\
\hline & (1) & $(2)$ & (3) & (4) & $(5)$ & (6) & (7) & (8) & (9) \\
\hline Treatment $\times$ Post & $\begin{array}{l}-0.1036^{* * *} \\
(0.0214)\end{array}$ & $\begin{array}{c}*^{*}-0.0926^{* * *} \\
(0.0185)\end{array}$ & $\begin{array}{l}-0.0636^{* * *} \\
(0.0147)\end{array}$ & $\begin{array}{l}-0.1047^{* * *} \\
(0.0215)\end{array}$ & $\begin{array}{l}-0.0935^{* * *} \\
(0.0194)\end{array}$ & $\begin{array}{l}-0.0856^{* * *} \\
(0.0172)\end{array}$ & $\begin{array}{c}* 0.1047^{* * *} \\
(0.0217)\end{array}$ & $\begin{array}{c}0.0084^{*} \\
(0.0050)\end{array}$ & $\begin{array}{l}-0.0560^{* * *} \\
(0.0134)\end{array}$ \\
\hline Treatment $\times$ Post $\times$ HHI ZIP NAICS6 & $\begin{array}{l}0.2864^{* * *} \\
(0.0542)\end{array}$ & & & $\begin{array}{l}0.1724^{* * *} \\
(0.0565)\end{array}$ & & & $\begin{array}{l}0.1684^{* * *} \\
(0.0426)\end{array}$ & & \\
\hline Treatment $\times$ Post $\times$ HHI ZIP NAICS 4 & & $\begin{array}{l}0.3073^{* * *} \\
(0.0527)\end{array}$ & & $\begin{array}{l}0.1374^{* * *} \\
(0.0375)\end{array}$ & & & & & \\
\hline Treatment $\times$ Post $\times$ HHI ZIP NAICS2 & & & $\begin{array}{l}0.2466^{* * *} \\
(0.0459)\end{array}$ & $\begin{array}{c}0.0265 \\
(0.0309)\end{array}$ & & & & & \\
\hline Treatment $\times$ Post $\times$ HHI County NAICS6 & & & & & $\begin{array}{l}0.3092^{* * *} \\
(0.0575)\end{array}$ & & $\begin{array}{c}0.0443 \\
(0.0373)\end{array}$ & & \\
\hline Treatment $\times$ Post $\times$ HHI State NAICS6 & & & & & & $\begin{array}{l}0.2793^{* * *} \\
(0.0475)\end{array}$ & $\begin{array}{c}0.1182^{* * *} \\
(0.0322)\end{array}$ & & \\
\hline Treatment $\times$ Post $\times \#$ other brands & & & & & & & & $\begin{array}{l}-0.0061^{* *} \\
(0.0011)\end{array}$ & \\
\hline Treatment $\times$ Post $\times$ One competing brand & & & & & & & & & $\begin{array}{l}0.0683^{* * *} \\
(0.0130)\end{array}$ \\
\hline Lawsuit x Outlet FE & Yes & Yes & Yes & Yes & Yes & Yes & Yes & Yes & Yes \\
\hline Lawsuit x ZIP x NAICS x Month FE & Yes & Yes & Yes & Yes & Yes & Yes & Yes & Yes & Yes \\
\hline $\mathrm{N}$ & $2,099,633$ & $2,099,633$ & $2,099,633$ & $2,099,633$ & $2,099,633 \quad 2$ & $2,099,633$ & $2,099,633$ & $2,099,633$ & $2,099,633$ \\
\hline$R^{2}$ & 0.977 & 0.977 & 0.977 & 0.977 & 0.977 & 0.977 & 0.977 & 0.977 & 0.977 \\
\hline
\end{tabular}


Table 4

\section{Alternative measures retail customer response to class action lawsuits}

This table presents results of ordinary least squares regressions using the logarithm of the number of monthly outlet visitors (Panel A) and a dummy variable set equal to one if a store is closed (Panel B) as the dependent variable. Treatment is a dummy variable set equal to one if an outlet belongs to a firm that is the target in a class action lawsuit, zero otherwise. Post is a dummy variable set equal to one for the month of the filing of the class action lawsuit and all months thereafter. The sample of treated outlets comprises 25,155 outlets associated with a firm involved in a class action lawsuit. From the Securities Class Action Clearinghouse database, we drop lawsuits involving financial firms (two-digit NAICS industry 52), lawsuits targeting firms headquartered outside of the U.S., lawsuits filed before March 1, 2018, lawsuits filed after February 29, 2020, and lawsuits for which we cannot match outlets in SafeGraph. For each treated outlet, we retain eleven monthly observations around the filing month of a lawsuit, five months before and five months after. The control sample is constructed by selecting all monthly observations of outlets in the same ZIP code and six-digit NAICS industry as the treated outlets. Detailed descriptions of all variables used throughout the study are provided in the Appendix. Standard errors, reported in parentheses, are clustered at the firm - month level. ${ }^{* * *},{ }^{* *},{ }^{*}$ denote statistical significance at the $1 \%, 5 \%$, and $10 \%$ level, respectively.

Panel A: Monthly outlet visitors

\begin{tabular}{|c|c|c|c|c|c|c|}
\hline & \multicolumn{6}{|c|}{$\ln ($ Visitors $)$} \\
\hline & $(1)$ & $(2)$ & $(3)$ & $(4)$ & $(5)$ & $(6)$ \\
\hline Treatment $\times$ Post & $\begin{array}{l}-0.0476^{* * *} \\
(0.0144)\end{array}$ & $\begin{array}{l}-0.0644^{* * *} \\
(0.0095)\end{array}$ & $\begin{array}{l}-0.0359 * * * \\
(0.0099)\end{array}$ & $\begin{array}{l}-0.0959^{* * *} \\
(0.0197)\end{array}$ & $\begin{array}{c}0.0056 \\
(0.0044)\end{array}$ & $\begin{array}{l}-0.0533^{* * *} \\
(0.0122)\end{array}$ \\
\hline Post & $\begin{array}{l}0.1028^{* * *} \\
(0.0040)\end{array}$ & $\begin{array}{l}0.0180^{* * *} \\
(0.0049)\end{array}$ & & & & \\
\hline Treatment $\times$ Post $\times$ HHI ZIP NAICS6 & & & & $\begin{array}{l}0.2609 * * * \\
(0.0499)\end{array}$ & & \\
\hline Treatment $\times$ Post $\times \#$ other brands & & & & & $\begin{array}{l}-0.0055^{* * *} \\
(0.0011)\end{array}$ & \\
\hline Treatment $\times$ Post $\times$ One competing brand & & & & & & $\begin{array}{l}0.0649^{* * *} \\
(0.0117)\end{array}$ \\
\hline Lawsuit x Outlet FE & Yes & Yes & Yes & Yes & Yes & Yes \\
\hline Month FE & No & Yes & No & No & No & No \\
\hline Lawsuit x ZIP x NAICS x Month FE & No & No & Yes & Yes & Yes & Yes \\
\hline $\mathrm{N}$ & $2,099,633$ & $2,099,633$ & $2,099,633$ & $2,099,633$ & $2,099,633$ & $2,099,633$ \\
\hline$R^{2}$ & 0.973 & 0.975 & 0.980 & 0.980 & 0.980 & 0.980 \\
\hline
\end{tabular}


Panel B: Store closures

\begin{tabular}{|c|c|c|c|c|c|c|}
\hline & \multicolumn{6}{|c|}{$\ln$ (Visitors) } \\
\hline & (1) & $(2)$ & (3) & $(4)$ & $(5)$ & (6) \\
\hline Treatment $\times$ Post & $\begin{array}{l}0.1178^{* * *} \\
(0.0312)\end{array}$ & $\begin{array}{l}0.0766^{* * *} \\
(0.0274)\end{array}$ & $\begin{array}{l}-0.0182 \\
(0.0120)\end{array}$ & $\begin{array}{l}0.0302^{* *} \\
(0.0139)\end{array}$ & $\begin{array}{l}-0.0367^{*} \\
(0.0198)\end{array}$ & $\begin{array}{c}0.0121 \\
(0.0133)\end{array}$ \\
\hline Post & $\begin{array}{l}0.0607^{* * *} \\
(0.0071)\end{array}$ & $\begin{array}{l}-0.0170^{*} \\
(0.0103)\end{array}$ & & & & \\
\hline Treatment $\times$ Post $\times$ HHI ZIP NAICS6 & & & & $\begin{array}{l}-0.2105^{* * *} \\
(0.0605)\end{array}$ & & \\
\hline Treatment $\times$ Post $\times \#$ other brands & & & & & $\begin{array}{l}0.0024^{* *} \\
(0.0011)\end{array}$ & \\
\hline Treatment $\times$ Post $\times$ One competing brand & & & & & & $\begin{array}{l}-0.1132^{* * *} \\
(0.0296)\end{array}$ \\
\hline Lawsuit x Outlet FE & Yes & Yes & Yes & Yes & Yes & Yes \\
\hline Month FE & No & Yes & No & No & No & No \\
\hline Lawsuit x ZIP x NAICS x Month FE & No & No & Yes & Yes & Yes & Yes \\
\hline $\mathrm{N}$ & $2,099,633$ & $2,099,633$ & $2,099,633$ & $2,099,633$ & $2,099,633$ & $2,099,633$ \\
\hline$R^{2}$ & 0.686 & 0.686 & 0.782 & 0.782 & 0.782 & 0.782 \\
\hline
\end{tabular}


Table 5

Outlet characteristics and retail customer response

This table presents results of ordinary least squares regressions using the logarithm of the monthly number of outlet visits as the dependent variable. Treatment is a dummy variable set equal to one if an outlet belongs to a firm that is the target in a class action lawsuit, zero otherwise. Post is a dummy variable set equal to one for the month of the filing of the class action lawsuit and all months thereafter. The sample of treated outlets comprises 25,155 outlets associated with a firm involved in a class action lawsuit. From the Securities Class Action Clearinghouse database, we drop lawsuits involving financial firms (two-digit NAICS industry 52), lawsuits targeting firms headquartered outside of the U.S., lawsuits filed before March 1, 2018, lawsuits filed after February 29, 2020, and lawsuits for which we cannot match outlets in SafeGraph. For each treated outlet, we retain eleven monthly observations around the filing month of a lawsuit, five months before and five months after. The control sample is constructed by selecting all monthly observations of outlets in the same ZIP code and six-digit NAICS industry as the treated outlets. Detailed descriptions of all variables used throughout the study are provided in the Appendix. Standard errors, reported in parentheses, are clustered at the firm - month level. ${ }^{* * *},{ }^{* *}, *$ denote statistical significance at the $1 \%, 5 \%$, and $10 \%$ level, respectively.

\begin{tabular}{|c|c|c|c|c|c|}
\hline & & & $\ln$ (Visits) & & \\
\hline & (1) & (2) & (3) & (4) & (5) \\
\hline Treatment $\times$ Post & $\begin{array}{l}-0.1337^{* * *} \\
(0.0238)\end{array}$ & $\begin{array}{l}-0.0670^{* * *} \\
(0.0203)\end{array}$ & $\begin{array}{l}-0.0869^{* * *} \\
(0.0201)\end{array}$ & $\begin{array}{l}-0.1080^{* * *} \\
(0.0219)\end{array}$ & $\begin{array}{l}-0.0560^{* * *} \\
(0.0171)\end{array}$ \\
\hline Treatment $\times$ Post $\times$ HHI ZIP NAICS6 & $\begin{array}{l}0.2834^{* * *} \\
(0.0543)\end{array}$ & $\begin{array}{l}0.2804^{* * *} \\
(0.0532)\end{array}$ & $\begin{array}{l}0.2646^{* * *} \\
(0.0521)\end{array}$ & $\begin{array}{l}0.2872^{* * *} \\
(0.0546)\end{array}$ & $\begin{array}{l}0.2656^{* * *} \\
(0.0513)\end{array}$ \\
\hline Treatment $\times$ Post $\times \ln ($ Distance to HQ $)$ & $\begin{array}{l}0.0045^{* *} \\
(0.0021)\end{array}$ & & & & \\
\hline Treatment $\times$ Post $\times$ Religious $(\%)$ & & $\begin{array}{l}-0.0648^{* * *} \\
(0.0130)\end{array}$ & & & \\
\hline Treatment $\times$ Post $\times$ Protestants $(\%)$ & & & $\begin{array}{l}-0.0522^{* * *} \\
(0.0147)\end{array}$ & & \\
\hline Treatment $\times$ Post $\times$ Catholics $(\%)$ & & & $\begin{array}{l}0.0283^{* *} \\
(0.0140)\end{array}$ & & \\
\hline Treatment $\times$ Post $\times$ Social capital & & & & $\begin{array}{l}-0.0063^{* *} \\
(0.0030)\end{array}$ & \\
\hline Treatment $\times$ Post $\times$ Republican $(\%)$ & & & & & $\begin{array}{l}-0.0924^{* * *} \\
(0.0152)\end{array}$ \\
\hline Lawsuit x Outlet FE & Yes & Yes & Yes & Yes & Yes \\
\hline Lawsuit x ZIP x NAICS x Month FE & Yes & Yes & Yes & Yes & Yes \\
\hline $\mathrm{N}$ & $2,099,633$ & $2,062,975$ & $2,062,975$ & $2,089,237$ & $2,089,795$ \\
\hline$R^{2}$ & 0.977 & 0.977 & 0.977 & 0.976 & 0.977 \\
\hline
\end{tabular}




\section{Table 6 \\ Descriptive statistics - announcement return sample}

This table presents descriptive statistics for the class action lawsuit panel. From the Securities Class Action Clearinghouse database, we drop lawsuits involving financial firms (two-digit NAICS industry 52), lawsuits targeting firms headquartered outside of the U.S., lawsuits involving firms headquartered outside of the U.S., lawsuits whose outcome are unknown ("ongoing"), and lawsuits that are remanded to another court. We also retain only lawsuits for which we can compute cumulative abnormal returns around the filing date, which requires non-missing stock return observations in the 12-day event window and at least 90 non-missing return observations in the estimation window. Detailed descriptions of all variables used throughout the study are provided in the Appendix.

\begin{tabular}{lccccc}
\hline & Mean & Std & $\mathrm{p} 25$ & $\mathrm{p} 50$ & $\mathrm{p} 75$ \\
\hline Announcement return & & & & & \\
CAR(-10,1) & -9.854 & 25.425 & -19.383 & -3.831 & 2.761 \\
Competition & & & & & \\
HHI NAICS6 & 0.305 & 0.244 & 0.130 & 0.212 & 0.392 \\
\# other firms & 101.796 & 136.463 & 9.000 & 33.000 & 154.000 \\
No competing firm & 0.030 & 0.171 & 0.000 & 0.000 & 0.000 \\
HHI HP & 0.220 & 0.215 & 0.079 & 0.140 & 0.270 \\
Product similarity HP & 6.282 & 8.966 & 1.376 & 2.946 & 7.078 \\
Lawsuit and firm characteristics & & & & & \\
Settled & 0.479 & 0.500 & 0.000 & 0.000 & 1.000 \\
Market cap. (USDm) & 5768.347 & 23051.236 & 152.612 & 568.413 & 2220.625 \\
Leverage & 0.232 & 0.247 & 0.005 & 0.172 & 0.380 \\
ROE & -0.101 & 0.515 & -0.106 & -0.003 & 0.031 \\
MTB & 3.459 & 6.266 & 1.136 & 2.165 & 4.120 \\
PPE/AT & 0.206 & 0.211 & 0.057 & 0.124 & 0.272 \\
Foreign revenue (\%) & 0.013 & 0.061 & 0.000 & 0.000 & 0.000 \\
Idiosyncratic vola & 0.043 & 0.024 & 0.025 & 0.037 & 0.056 \\
ILLIQ & 0.153 & 0.667 & 0.001 & 0.004 & 0.031 \\
\hline N & 3,322 & & & & \\
\hline
\end{tabular}


Table 7

Competition and stock market response to class action lawsuits

The dependent variable is cumulative abnormal return (CAR) around the class action filing date. The construction of the sample is described in Table 6. Variables are described in the Appendix. Robust standard errors are reported in parentheses. ${ }^{* * *},{ }^{* *},{ }^{*}$ denote statistical significance at the $1 \%, 5 \%$, and $10 \%$ level, respectively.

\begin{tabular}{|c|c|c|c|c|c|c|c|c|c|c|}
\hline & \multicolumn{10}{|c|}{$\operatorname{CAR}(-10,1)$} \\
\hline & (1) & $(2)$ & (3) & (4) & $(5)$ & (6) & (7) & $(8)$ & (9) & (10) \\
\hline HHI NAICS6 & $\begin{array}{c}3.7874^{* *} \\
(1.7732)\end{array}$ & $\begin{array}{c}3.9191^{* *} \\
(1.8123)\end{array}$ & & & & & & & & \\
\hline \# other firms & & & $\begin{array}{l}-0.0088^{* *} \\
(0.0041)\end{array}$ & $\begin{array}{l}-0.0089^{* *} \\
(0.0044)\end{array}$ & & & & & & \\
\hline No competing firm & & & & & $\begin{array}{l}4.8316^{* * *} \\
(1.6583)\end{array}$ & $\begin{array}{c}4.1721^{* *} \\
(1.6930)\end{array}$ & & & & \\
\hline HHI HP & & & & & & & $\begin{array}{l}-2.6367 \\
(2.3175)\end{array}$ & $\begin{array}{l}-0.0870 \\
(2.3794)\end{array}$ & & \\
\hline Product similarity HP & & & & & & & & & $\begin{array}{l}-0.3674^{* * *} \\
(0.0699)\end{array}$ & $\begin{array}{l}-0.4016^{* * *} \\
(0.0724)\end{array}$ \\
\hline Settled & & $\begin{array}{l}-7.2248^{* * *} \\
(1.1140)\end{array}$ & & $\begin{array}{l}-7.2299^{* * *} \\
(1.1148)\end{array}$ & & $\begin{array}{l}-7.2022^{* * *} \\
(1.0808)\end{array}$ & & $\begin{array}{l}-7.2349^{* * *} \\
(1.1470)\end{array}$ & & $\begin{array}{l}-6.9440^{* * *} \\
(1.1385)\end{array}$ \\
\hline $\ln$ (Market cap.) & & $\begin{array}{l}-0.0051 \\
(0.2954)\end{array}$ & & $\begin{array}{c}0.0127 \\
(0.2970)\end{array}$ & & $\begin{array}{l}-0.0059 \\
(0.2906)\end{array}$ & & $\begin{array}{c}0.1828 \\
(0.3448)\end{array}$ & & $\begin{array}{c}0.3223 \\
(0.3416)\end{array}$ \\
\hline Leverage & & $\begin{array}{l}-1.3236 \\
(2.1945)\end{array}$ & & $\begin{array}{l}-1.6174 \\
(2.2090)\end{array}$ & & $\begin{array}{l}-0.8086 \\
(2.1441)\end{array}$ & & $\begin{array}{l}-3.1559 \\
(2.5796)\end{array}$ & & $\begin{array}{l}-3.7106 \\
(2.4723)\end{array}$ \\
\hline $\mathrm{ROE}$ & & $\begin{array}{l}-0.9896 \\
(1.1295)\end{array}$ & & $\begin{array}{l}-1.0576 \\
(1.1319)\end{array}$ & & $\begin{array}{l}-1.0039 \\
(1.1230)\end{array}$ & & $\begin{array}{l}-1.7410 \\
(1.3230)\end{array}$ & & $\begin{array}{l}-1.9852 \\
(1.2921)\end{array}$ \\
\hline MTB & & $\begin{array}{l}-0.4916^{* * *} \\
(0.0873)\end{array}$ & & $\begin{array}{l}-0.4872^{* * *} \\
(0.0870)\end{array}$ & & $\begin{array}{l}-0.4609^{* * *} \\
(0.0843)\end{array}$ & & $\begin{array}{l}-0.6059^{* * *} \\
(0.1140)\end{array}$ & & $\begin{array}{l}-0.5865^{* * *} \\
(0.1134)\end{array}$ \\
\hline $\mathrm{PPE} / \mathrm{AT}$ & & $\begin{array}{l}7.4367^{* * *} \\
(2.1876)\end{array}$ & & $\begin{array}{l}6.4902^{* * *} \\
(2.2255)\end{array}$ & & $\begin{array}{l}7.4599 * * * \\
(2.0682)\end{array}$ & & $\begin{array}{l}9.2510^{* * *} \\
(2.5714)\end{array}$ & & $\begin{array}{l}8.1985^{* * *} \\
(2.5036)\end{array}$ \\
\hline Foreign revenue $(\%)$ & & $\begin{array}{c}4.6642 \\
(8.9466)\end{array}$ & & $\begin{array}{c}5.2434 \\
(8.9623)\end{array}$ & & $\begin{array}{c}5.0463 \\
(8.9033)\end{array}$ & & $\begin{array}{c}2.8625 \\
(9.3146)\end{array}$ & & $\begin{array}{c}2.8001 \\
(9.3696)\end{array}$ \\
\hline Idiosyncratic vola & & $\begin{array}{c}37.5080 \\
(32.2171)\end{array}$ & & $\begin{array}{c}45.7359 \\
(33.3546)\end{array}$ & & $\begin{array}{c}21.8795 \\
(31.2456)\end{array}$ & & $\begin{array}{c}55.9288 \\
(39.9639)\end{array}$ & & $\begin{array}{c}95.7842^{* *} \\
(41.1339)\end{array}$ \\
\hline ILLIQ & & $\begin{array}{c}0.9056 \\
(1.1103)\end{array}$ & & $\begin{array}{c}0.8892 \\
(1.1044)\end{array}$ & & $\begin{array}{c}1.2793 \\
(1.0275)\end{array}$ & & $\begin{array}{c}1.2525 \\
(1.4284)\end{array}$ & & $\begin{array}{c}0.7326 \\
(1.4276)\end{array}$ \\
\hline Year FE & No & Yes & No & Yes & No & Yes & No & Yes & No & Yes \\
\hline $\mathrm{N}$ & 3,074 & 2,878 & 3,074 & 2,878 & 3,322 & 3,027 & 2,517 & 2,377 & 2,579 & 2,432 \\
\hline$R^{2}$ & 0.001 & 0.117 & 0.002 & 0.117 & 0.001 & 0.110 & 0.000 & 0.116 & 0.016 & 0.130 \\
\hline
\end{tabular}




\section{Table 8}

\section{Descriptive statistics - quarterly firm sample}

This table presents descriptive statistics for the firm-quarter panel. The treatment sample comprises firms targeted by 3,582 class action lawsuits. We drop lawsuits involving financial firms (two-digit NAICS industry 52), lawsuits involving firms headquartered outside of the U.S., lawsuits whose outcome are unknown ("ongoing"), and lawsuits that are remanded to another court. For each treated firm, we retain eight quarterly observations around the filing quarter of a lawsuit, four quarters before and three quarters after. The control sample is constructed by selecting all quarterly observations of firms in the same six-digit NAICS industry as the treated firms. Detailed descriptions of all variables used throughout the study are provided in the Appendix.

\begin{tabular}{lccccc}
\hline & Mean & Std & $\mathrm{p} 25$ & $\mathrm{p} 50$ & $\mathrm{p} 75$ \\
\hline Revenue & & & & & \\
Revenue (USDm) & 223.380 & 1677.069 & 2.142 & 10.657 & 50.446 \\
Treatment & 0.012 & 0.111 & 0.000 & 0.000 & 0.000 \\
Competition & & & & & \\
HHI NAICS6 & 0.161 & 0.114 & 0.090 & 0.134 & 0.189 \\
\# other firms & 232.519 & 154.952 & 120.000 & 180.000 & 406.000 \\
One competing firm & 0.001 & 0.031 & 0.000 & 0.000 & 0.000 \\
HHI HP & 0.196 & 0.207 & 0.076 & 0.118 & 0.221 \\
Product similarity HP & 8.819 & 11.529 & 1.825 & 4.319 & 10.799 \\
Lawsuit characteristics & & & & & \\
CAR (-10,1) & -10.946 & 28.315 & -23.718 & -4.861 & 4.776 \\
Settled & 0.491 & 0.500 & 0.000 & 0.000 & 1.000 \\
\hline $\mathrm{N}$ & $1,969,528$ & & & & \\
\hline
\end{tabular}




\section{Table 9}

\section{Revenue response to class action lawsuits}

This table presents results of ordinary least squares regressions using the logarithm of quarterly revenue as the dependent variable. Treatment is a dummy variable set equal to one if a firm is the target in a class action lawsuit, zero otherwise. Post is a dummy variable set equal to one for the quarter of the filing of the class action lawsuit and all quarters thereafter. The treatment sample comprises firms targeted by 3,582 class action lawsuits. We drop lawsuits involving financial firms (two-digit NAICS industry 52), lawsuits involving firms headquartered outside of the U.S., lawsuits whose outcome are unknown ("ongoing"), and lawsuits that are remanded to another court. For each treated firm, we retain eight quarterly observations around the filing quarter of a lawsuit, four quarters before and three quarters after. The control sample is constructed by selecting all quarterly observations of firms in the same six-digit NAICS industry as the treated firms. Detailed descriptions of all variables used throughout the study are provided in the Appendix. Standard errors, reported in parentheses, are clustered at the class action lawsuit - firm level. ${ }^{* * *},{ }^{* *},{ }^{*}$ denote statistical significance at the $1 \%, 5 \%$, and $10 \%$ level, respectively.

\begin{tabular}{lcccc}
\hline & \multicolumn{3}{c}{$\ln$ (Revenue) } \\
\cline { 2 - 5 } & $(1)$ & $(2)$ & $(3)$ & $(4)$ \\
\hline Treatment $\times$ Post & $-0.0976^{* * *}$ & $-0.0876^{* * *}$ & $-0.0862^{* * *}$ & $-0.0921^{* * *}$ \\
& $(0.0102)$ & $(0.0105)$ & $(0.0105)$ & $(0.0157)$ \\
Post & $0.0885^{* * *}$ & -0.0014 & & \\
& $(0.0014)$ & $(0.0016)$ & & \\
Lawsuit x Firm FE & Yes & Yes & Yes & Yes \\
NAICS x Quarter FE & No & Yes & No & No \\
Lawsuit x NAICS x Quarter FE & No & No & Yes & No \\
Lawsuit x NAICS x Quarter x State FE & No & No & No & Yes \\
\hline $\mathrm{N}$ & $1,969,528$ & $1,969,528$ & $1,969,528$ & $1,965,778$ \\
$R^{2}$ & 0.961 & 0.962 & 0.962 & 0.969 \\
\hline
\end{tabular}


Table 10

\section{Competition and revenue response to class action lawsuits}

This table presents results of ordinary least squares regressions using the logarithm of quarterly revenue as the dependent variable. Treatment is a dummy variable set equal to one if a firm is the target in a class action lawsuit, zero otherwise. Post is a dummy variable set equal to one for the quarter of the filing of the class action lawsuit and all quarters thereafter. The treatment sample comprises firms targeted by 3,582 class action lawsuits. From the Securities Class Action Clearinghouse database, we drop lawsuits involving financial firms (two-digit NAICS industry 52), lawsuits involving firms headquartered outside of the U.S., lawsuits whose outcome are unknown ("ongoing"), and lawsuits that are remanded to another court. For each treated firm, we retain eight quarterly observations around the filing quarter of a lawsuit, four quarters before and three quarters after. The control sample is constructed by selecting all quarterly observations of firms in the same six-digit NAICS industry as the treated firms. Detailed descriptions of all variables used throughout the study are provided in the Appendix. Standard errors, reported in parentheses, are clustered at the class action lawsuit - firm level. $* * *, * *, *$ denote statistical significance at the $1 \%, 5 \%$, and $10 \%$ level, respectively.

\begin{tabular}{|c|c|c|c|c|c|}
\hline \multirow[b]{2}{*}{ Metric: } & \multicolumn{5}{|c|}{$\ln$ (Revenue) } \\
\hline & $\begin{array}{c}(1) \\
\text { HHI NAICS6 }\end{array}$ & $\begin{array}{c}(2) \\
\text { \# other firms }\end{array}$ & $\begin{array}{c}(3) \\
\text { One comp. firm }\end{array}$ & $\begin{array}{c}(4) \\
\text { HHI HP }\end{array}$ & $\begin{array}{l}(5) \\
\text { Prod. similarity HP }\end{array}$ \\
\hline Treatment $\times$ Post $\times$ Metric & $\begin{array}{l}0.1361^{* * *} \\
(0.0396)\end{array}$ & $\begin{array}{l}-0.0002^{* *} \\
(0.0001)\end{array}$ & $\begin{array}{l}0.1129^{* *} \\
(0.0553)\end{array}$ & $\begin{array}{l}0.1249^{* * * *} \\
(0.0472)\end{array}$ & $\begin{array}{c}0.0002 \\
(0.0031)\end{array}$ \\
\hline Treatment $\times$ Post & $\begin{array}{l}-0.1207^{* * *} \\
(0.0169)\end{array}$ & $\begin{array}{l}-0.0619^{* * *} \\
(0.0113)\end{array}$ & $\begin{array}{l}-0.0989^{* * *} \\
(0.0105)\end{array}$ & $\begin{array}{l}-0.0974^{* * *} \\
(0.0175)\end{array}$ & $\begin{array}{l}-0.0670^{* * *} \\
(0.0168)\end{array}$ \\
\hline Treatment $\times$ Metric & $\begin{array}{l}0.3583^{* *} \\
(0.1590)\end{array}$ & $\begin{array}{l}-0.0002 \\
(0.0010)\end{array}$ & $\begin{array}{l}-0.1353 \\
(0.0880)\end{array}$ & $\begin{array}{c}0.0341 \\
(0.0609)\end{array}$ & $\begin{array}{c}0.0026 \\
(0.0052)\end{array}$ \\
\hline Post $\times$ Metric & $\begin{array}{l}-0.1415^{* * *} \\
(0.0109)\end{array}$ & $\begin{array}{l}0.0002^{* * *} \\
(0.0000)\end{array}$ & $\begin{array}{l}-0.0786^{*} \\
(0.0440)\end{array}$ & $\begin{array}{l}-0.1073^{* * *} \\
(0.0077)\end{array}$ & $\begin{array}{l}0.0023^{* * *} \\
(0.0002)\end{array}$ \\
\hline Metric & $\begin{array}{l}-0.8354^{* * *} \\
(0.0320)\end{array}$ & $\begin{array}{l}0.0018^{* * *} \\
(0.0000)\end{array}$ & $\begin{array}{l}0.1089 \\
(0.0713)\end{array}$ & $\begin{array}{l}-0.1511^{* * *} \\
(0.0114)\end{array}$ & $\begin{array}{l}0.0095^{* * *} \\
(0.0007)\end{array}$ \\
\hline Post & $\begin{array}{l}0.1166^{* * *} \\
(0.0023)\end{array}$ & $\begin{array}{l}0.0620^{* * *} \\
(0.0024)\end{array}$ & $\begin{array}{l}0.0885^{* * *} \\
(0.0014)\end{array}$ & $\begin{array}{l}0.0821^{* * * *} \\
(0.0022)\end{array}$ & $\begin{array}{l}0.0443^{* * *} \\
(0.0020)\end{array}$ \\
\hline Lawsuit x Firm FE & Yes & Yes & Yes & Yes & Yes \\
\hline $\mathrm{N}$ & $1,969,528$ & $1,969,528$ & $1,969,528$ & $1,266,448$ & $1,269,039$ \\
\hline$R^{2}$ & 0.961 & 0.961 & 0.961 & 0.961 & 0.961 \\
\hline
\end{tabular}




\section{Table 11}

\section{Lawsuit characteristics and revenue response to class action lawsuits}

This table presents results of ordinary least squares regressions using the logarithm of quarterly revenue as the dependent variable. Treatment is a dummy variable set equal to one if a firm is the target in a class action lawsuit, zero otherwise. Post is a dummy variable set equal to one for the quarter of the filing of the class action lawsuit and all quarters thereafter. The treatment sample comprises firms targeted by 3,582 class action lawsuits. From the Securities Class Action Clearinghouse database, we drop lawsuits involving financial firms (two-digit NAICS industry 52), lawsuits involving firms headquartered outside of the U.S., lawsuits whose outcome are unknown ("ongoing"), and lawsuits that are remanded to another court. For each treated firm, we retain eight quarterly observations around the filing quarter of a lawsuit, four quarters before and three quarters after. The control sample is constructed by selecting all quarterly observations of firms in the same six-digit NAICS industry as the treated firms. Detailed descriptions of all variables used throughout the study are provided in the Appendix. Standard errors, reported in parentheses, are clustered at the class action lawsuit - firm level. ${ }^{* *},{ }^{* *},{ }^{*}$ denote statistical significance at the $1 \%, 5 \%$, and $10 \%$ level, respectively.

\begin{tabular}{lcc}
\hline & \multicolumn{2}{c}{$\ln ($ Revenue $)$} \\
\cline { 2 - 3 } & $(1)$ & $(2)$ \\
\hline Treatment $\times$ Post $\times$ CAR $(-10,1)$ & $0.0012^{* *}$ & \\
Post $\times$ CAR $(-10,1)$ & $(0.0005)$ & \\
Treatment $\times$ Post $\times$ Settled & $-0.0011^{* * *}$ & $-0.0404^{*}$ \\
Post $\times$ Settled & $(0.0001)$ & $(0.0207)$ \\
Treatment $\times$ Post & & $-0.0445^{* * *}$ \\
Post & & $(0.0028)$ \\
Lawsuit $x$ Firm FE & $-0.0930^{* * *}$ & $-0.0818^{* * *}$ \\
N & $(0.0116)$ & $(0.0128)$ \\
$R^{2}$ & $0.0755^{* * *}$ & $0.1117^{* * *}$ \\
\hline
\end{tabular}




\section{Figure 1: Retail customer response to class action lawsuits}

This figure plots $90 \%$ confidence intervals and estimates from coefficients of the following regression:

$$
\ln \left(\text { Visits }_{i, s, t}=\beta_{t} \times \text { Treatment }_{i, s} \times{\text { Event } \text { mont }_{i, t}+\alpha_{i, s}+\alpha_{s, j, k, t}+\epsilon_{i, s, t},}\right.
$$

where $i$ indexes an outlet, $s$ a lawsuit, $t$ a month, $j$ an industry, and $k$ a ZIP code. Visits is the monthly number of visits at the outlet. Treatment is a dummy indicating whether the outlet belongs to the target of the lawsuit. Event month are dummies indicating months relative to the filing month. $\alpha_{i, s}$ are interacted lawsuit and outlet fixed effects. $\alpha_{s, j, k, t}$ are interacted lawsuit, six-digit NAICS industry, ZIP code, and month fixed effects. The sample of treated outlets comprises 25,155 outlets associated with a firm involved in a class action lawsuit. From the Securities Class Action Clearinghouse database, we drop lawsuits involving financial firms (two-digit NAICS industry 52), lawsuits targeting firms headquartered outside of the U.S., lawsuits filed before March 1, 2018, lawsuits filed after February 29, 2020, and lawsuits for which we cannot match outlets in SafeGraph. We also drop outlets for which we cannot match control outlets. For each treated outlet, we retain eleven monthly observations around the filing month of a lawsuit, five months before and five months after. The control sample is constructed by selecting all monthly observations of outlets in the same ZIP code and six-digit NAICS industry as the treated outlets. Detailed descriptions of all variables used throughout the study are provided in the Appendix. Standard errors are clustered at the firm - month level.

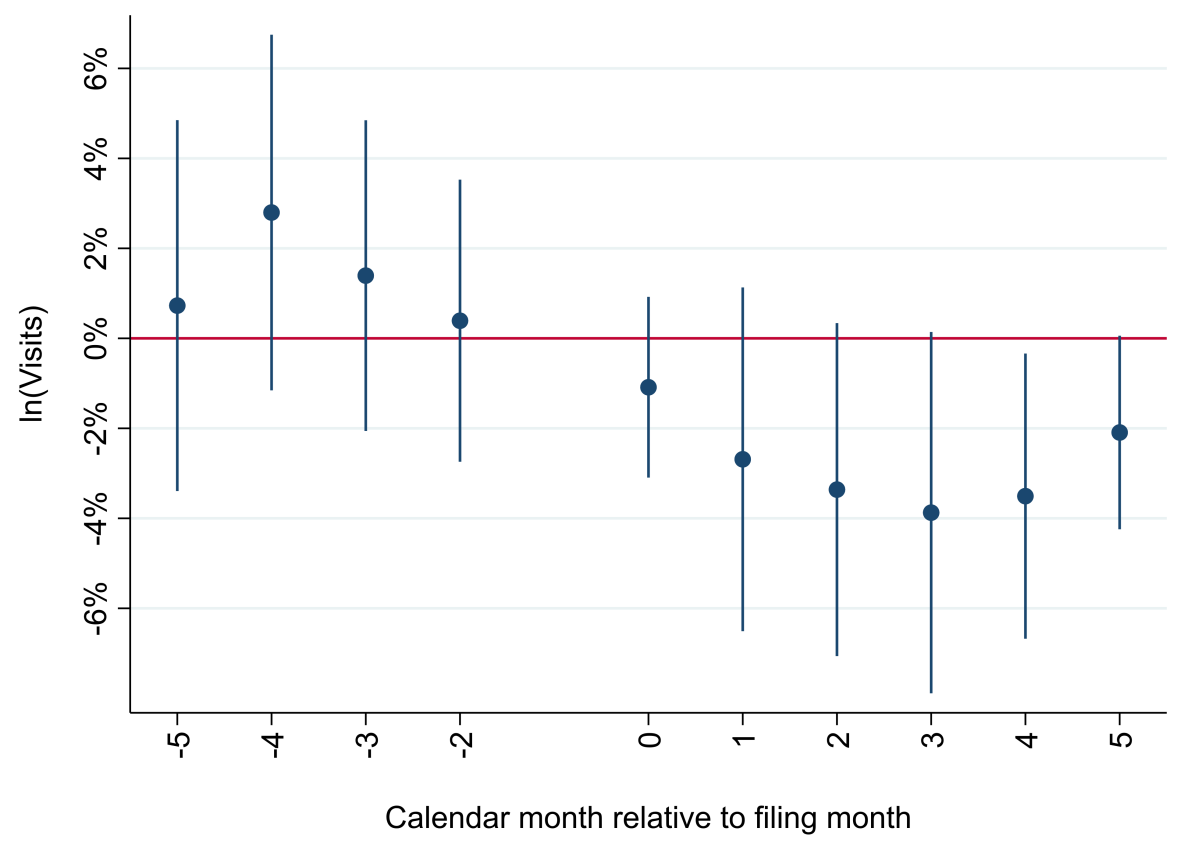




\section{Figure 2: Stock market response to class action lawsuits}

This figure plots means and 90\% confidence intervals for daily abnormal returns (ARs) from 15 trading days before to five trading days after the filing date of the class action lawsuits. Daily ARs are calculated as the observed return (ret) minus a predicted return. The predicted return is estimated using a market model regression where daily returns (ret) are regressed on daily value-weighted index returns (vwret) over a 250-day estimation window that ends eleven trading days prior to the event date. The shaded area highlights the 12-day asymmetric event window used in the analysis to compute cumulative abnormal returns. From the Securities Class Action Clearinghouse database, we drop lawsuits involving financial firms (two-digit NAICS industry 52), lawsuits involving firms headquartered outside of the U.S., lawsuits whose outcome are unknown ("ongoing"), and lawsuits that are remanded to another court. We also retain only lawsuits for which we can compute cumulative abnormal returns around the filing date, which requires non-missing stock return observations in the 12-day event window and at least 90 non-missing return observations in the estimation window.

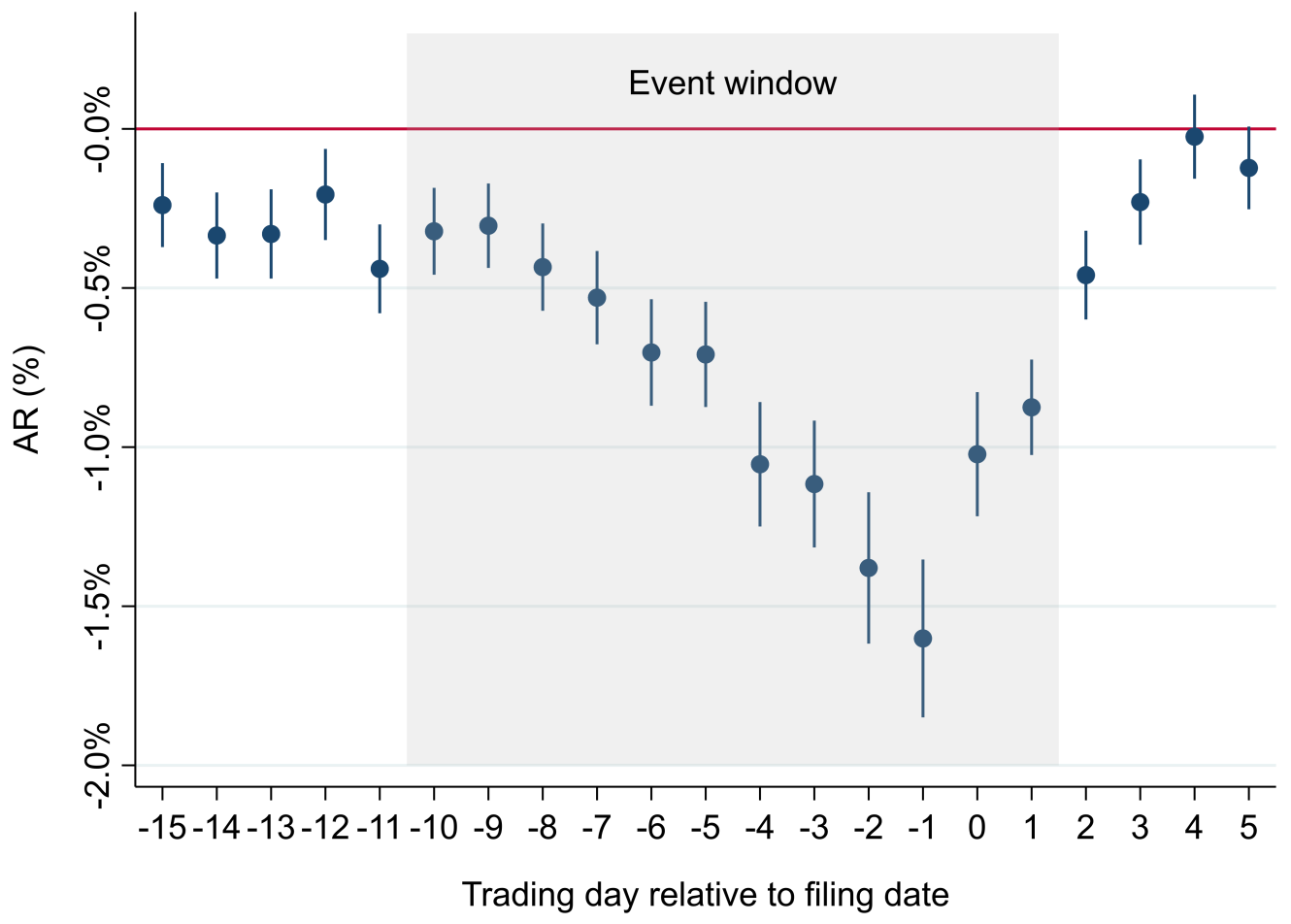




\section{Figure 3: Revenue response to class action lawsuits}

This figure plots $90 \%$ confidence intervals and estimates from coefficients of the following regression:

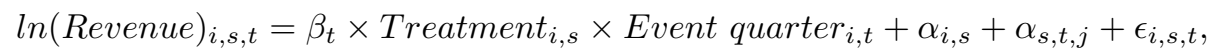

where $i$ indexes a firm, $s$ a lawsuit, $t$ a quarter, and $j$ an industry. Revenue is the quarterly revenue. Treatment is a dummy indicating whether the firm is the target of the lawsuit. Event quarter are dummies indicating quarters relative to the filing quarter. $\alpha_{i, s}$ are interacted lawsuit and firm fixed effects. $\alpha_{s, t, j}$ are interacted lawsuit, six-digit NAICS industry, and month fixed effects. The treatment sample comprises firms targeted by 3,582 class action lawsuits. From the Securities Class Action Clearinghouse database, we drop lawsuits involving financial firms (two-digit NAICS industry 52), lawsuits involving firms headquartered outside of the U.S., lawsuits whose outcome are unknown ("ongoing"), and lawsuits that are remanded to another court. For each treated firm, we retain 13 quarterly observations around the filing quarter of a lawsuit, four quarters before and eight quarters after. The control sample is constructed by selecting all quarterly observations of firms in the same six-digit NAICS industry as the treated firms. Detailed descriptions of all variables used throughout the study are provided in the Appendix. Standard errors are clustered at the class action lawsuit - firm level.

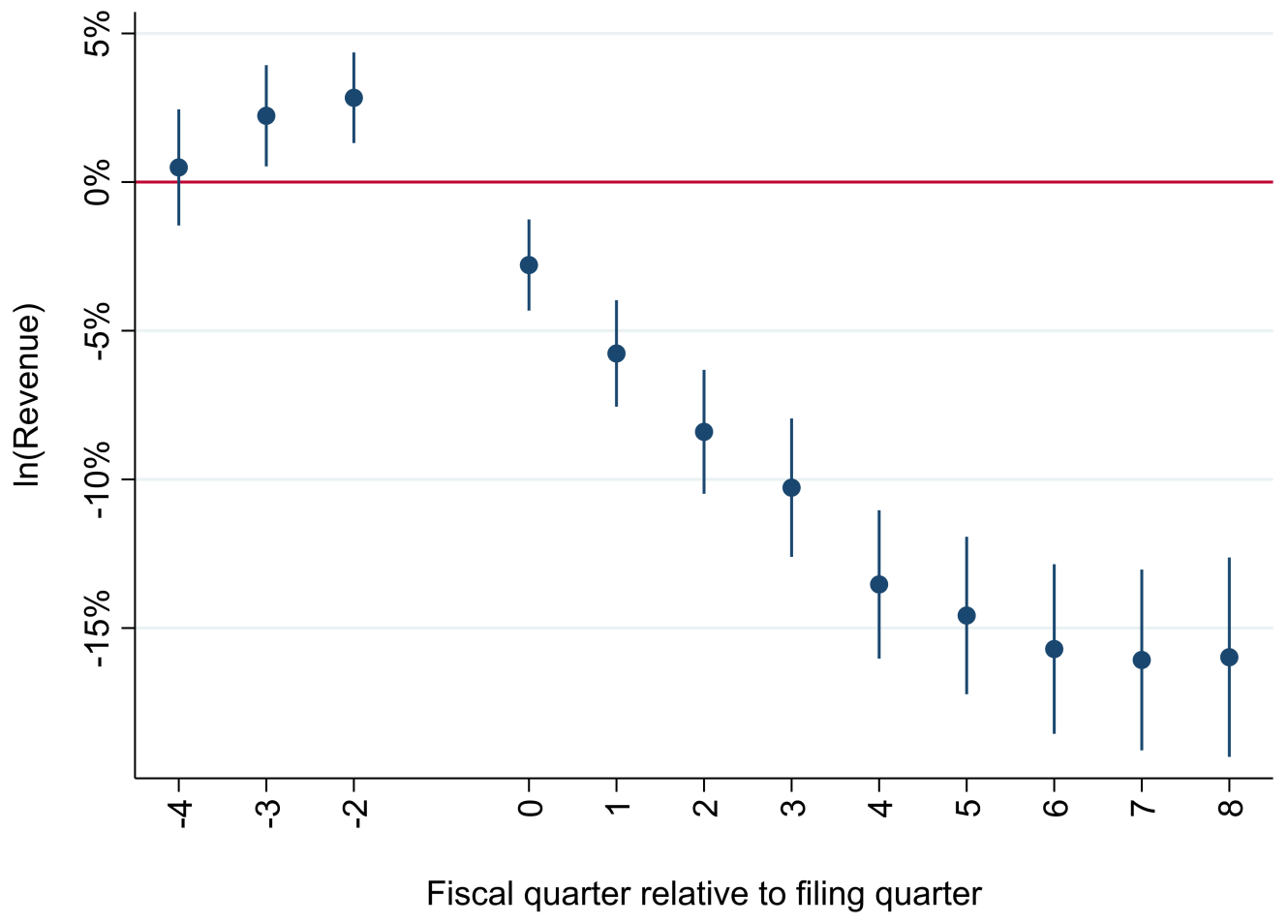




\section{Figure 4: News response to class action lawsuits}

This figure plots $90 \%$ confidence intervals and estimates from coefficients of the following regression:

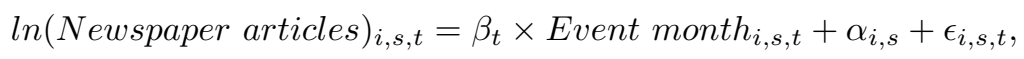

where $i$ indexes a firm, $s$ a lawsuit, and $t$ a calendar month. Newspaper articles is the number of articles mentioning the firm that is the target of a lawsuit from 5 calendar months before to 5 calendar months after the filing month. Event month are dummies indicating calendar months relative to the filing month. $\alpha_{i, s}$ are interacted lawsuit and firm fixed effects. The sample comprises 29 class action lawsuits. From the Securities Class Action Clearinghouse database, we drop lawsuits involving financial firms (two-digit NAICS industry 52), lawsuits filed before March 1, 2018, and lawsuits filed after February 29, 2020, and lawsuits for which we cannot match outlets in SafeGraph. We also drop firms for which we cannot match control outlets as described in Section 3.2 Standard errors are clustered at the lawsuit level.

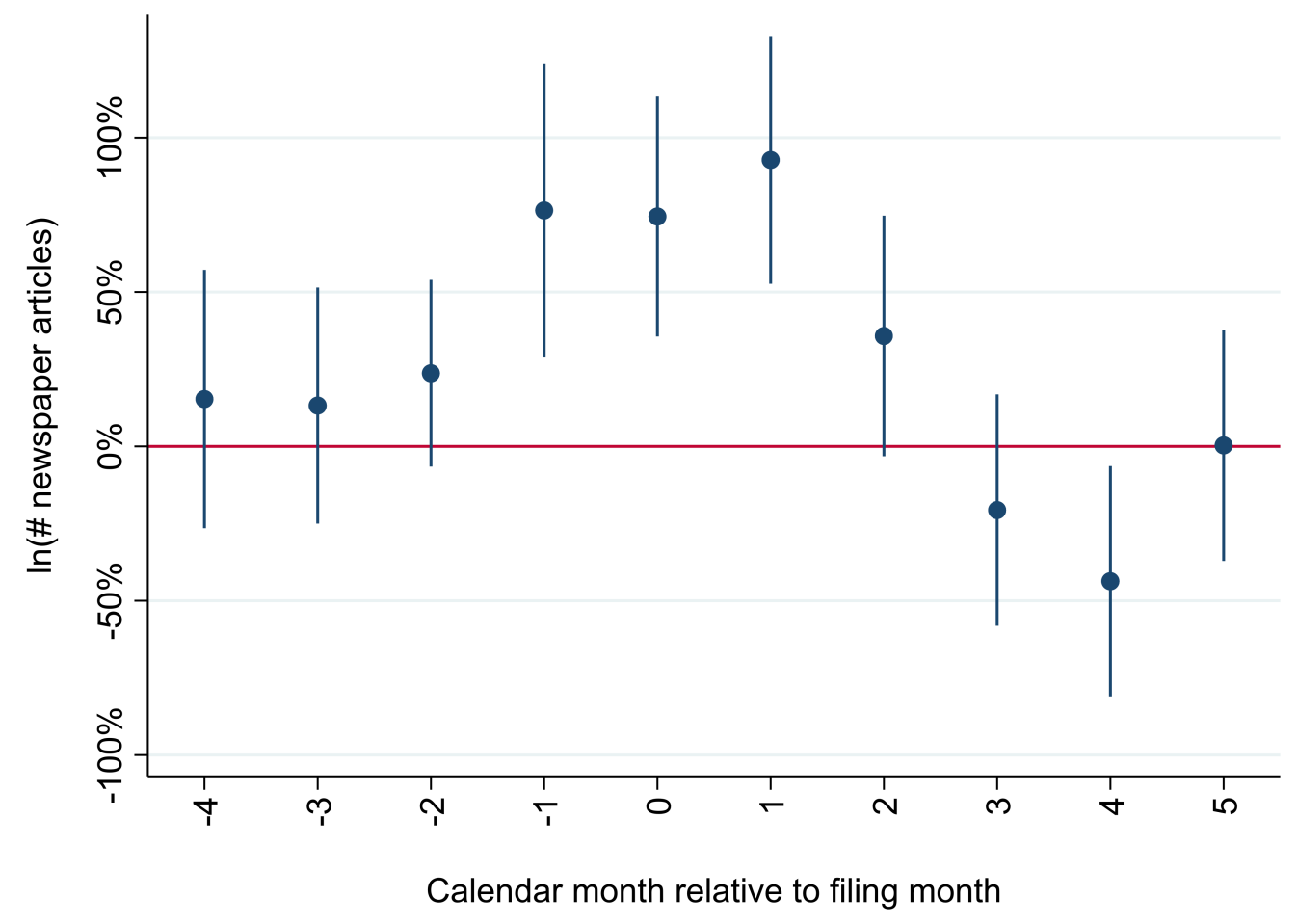




\section{Figure 5: Retail trader response to class action lawsuits}

This figure plots $90 \%$ confidence intervals and estimates from coefficients of the following regression:

$$
\ln (\# \text { Robinhood accounts })_{i, s, t}=\beta_{t} \times \text { Treatment }_{i, s} \times \text { Time }_{i, t}+\alpha_{i, s}+\alpha_{s, t, j}+\epsilon_{i, s, t},
$$

where $i$ indexes a firm, $s$ a lawsuit, $t$ time, and $j$ an industry. \# Robinhood accounts is the number of Robinhood accounts that a hold a given stock. Treatment is a dummy indicating whether a firm is the target of a lawsuit. Time are day (month) dummies indicating trading days (calendar months) relative to the filing day (month). $\alpha_{i, s}$ are interacted lawsuit and firm fixed effects. $\alpha_{s, t, j}$ are interacted lawsuit, six-digit NAICS industry, and time fixed effects. The sample of treated firms comprises 17 firms that are targeted by a class action lawsuit. From the Securities Class Action Clearinghouse database, we drop lawsuits involving financial firms (two-digit NAICS industry 52), lawsuits targeting firms headquartered outside of the U.S., lawsuits filed before May 2, 2018, lawsuits filed after February 29, 2020, lawsuits for which we cannot match outlets in SafeGraph, and lawsuits and for which we cannot match the number of Robinhood account holders. We also firms for which we cannot match control outlets as described in Section 3.2. Panel A plots estimates of a regression using 31 daily observations around the filing day of a lawsuit, 15 trading days before to 15 trading days after the filing date. Panel B plots estimates of a regression using eleven monthly observations around the filing quarter of a lawsuit, 5 months before to 5 months after the filing month. The control sample is constructed by selecting observations of 119 firms in the Robinhood data that are active in the same six-digit NAICS industry as the treated firms. Detailed descriptions of all variables used throughout the study are provided in the Appendix. Standard errors are clustered at the class action lawsuit - firm level.

Panel A: Daily account holders

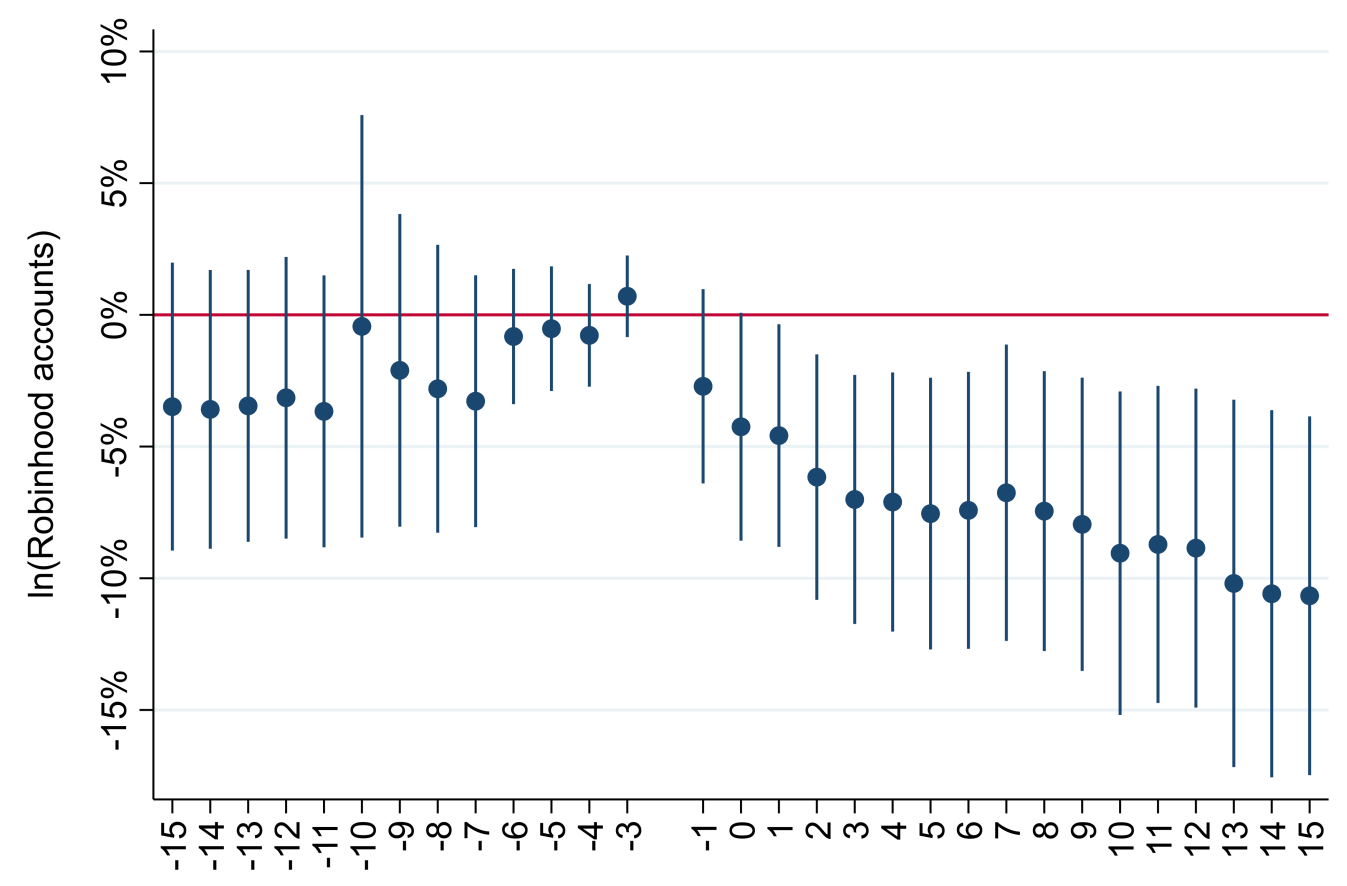

Trading day relative to filing date 
Panel B: Monthly account holders

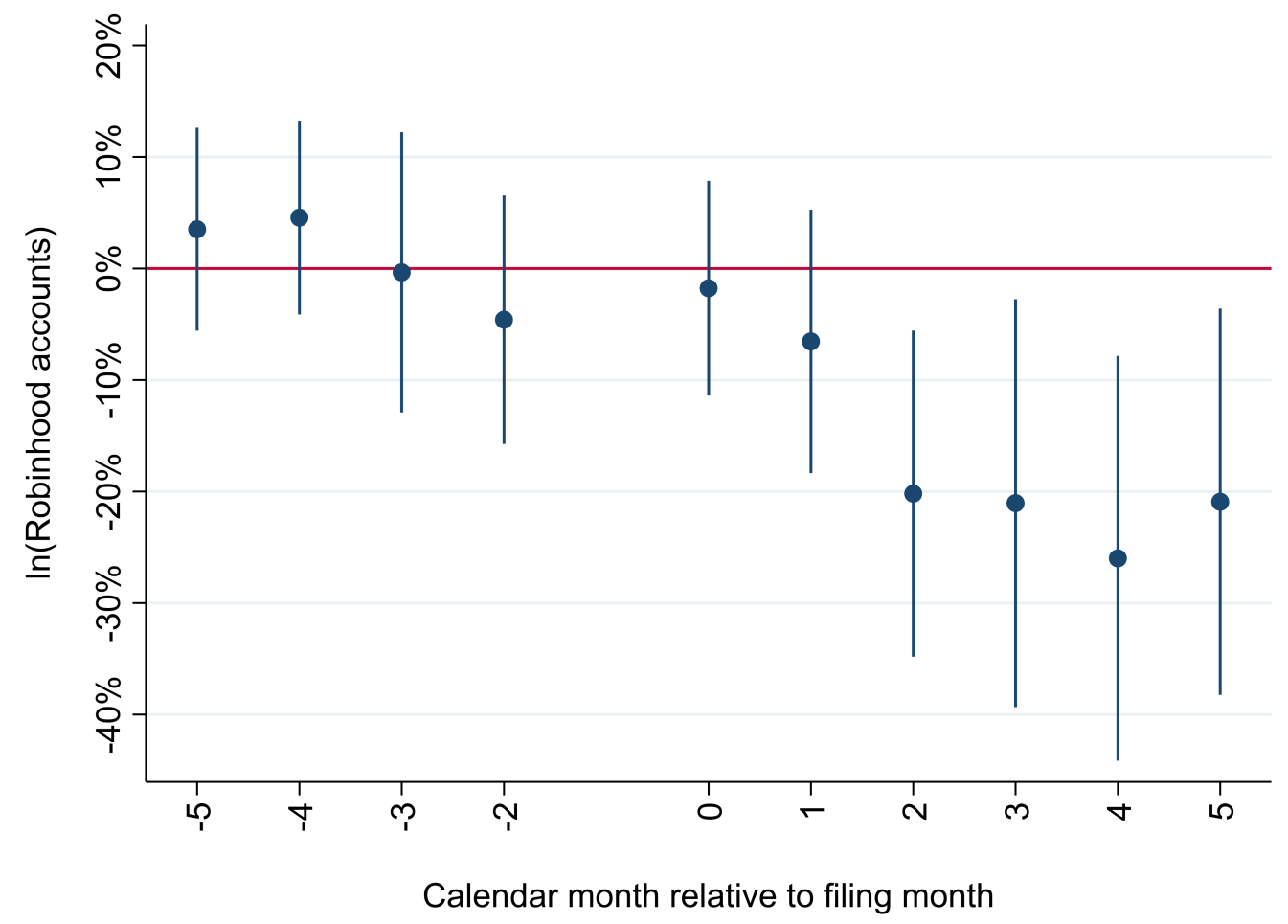




\section{A Internet Appendix}

\section{Figure A.1: Spatial distribution of outlets}

This figure shows the distribution of the locations of the treated outlets (red) and control outlets (blue) across the U.S. The sample of treated outlets comprises 25,155 outlets associated with a firm involved in a class action lawsuit. The sample of treated outlets comprises 25,155 outlets associated with a firm involved in a class action lawsuit. From the Securities Class Action Clearinghouse database, we drop lawsuits involving financial firms (two-digit NAICS industry 52), lawsuits targeting firms headquartered outside of the U.S., lawsuits filed before March 1, 2018, lawsuits filed after February 29, 2020, and lawsuits for which we cannot match outlets in SafeGraph. We also drop outlets for which we cannot match control outlets. The control sample is constructed by selecting all outlets in the same ZIP code and six-digit NAICS industry as the treated outlets, resulting in a control comprising 123,129 outlets. Black dots mark the locations of the headquarters of the firms involved in the class action lawsuits.

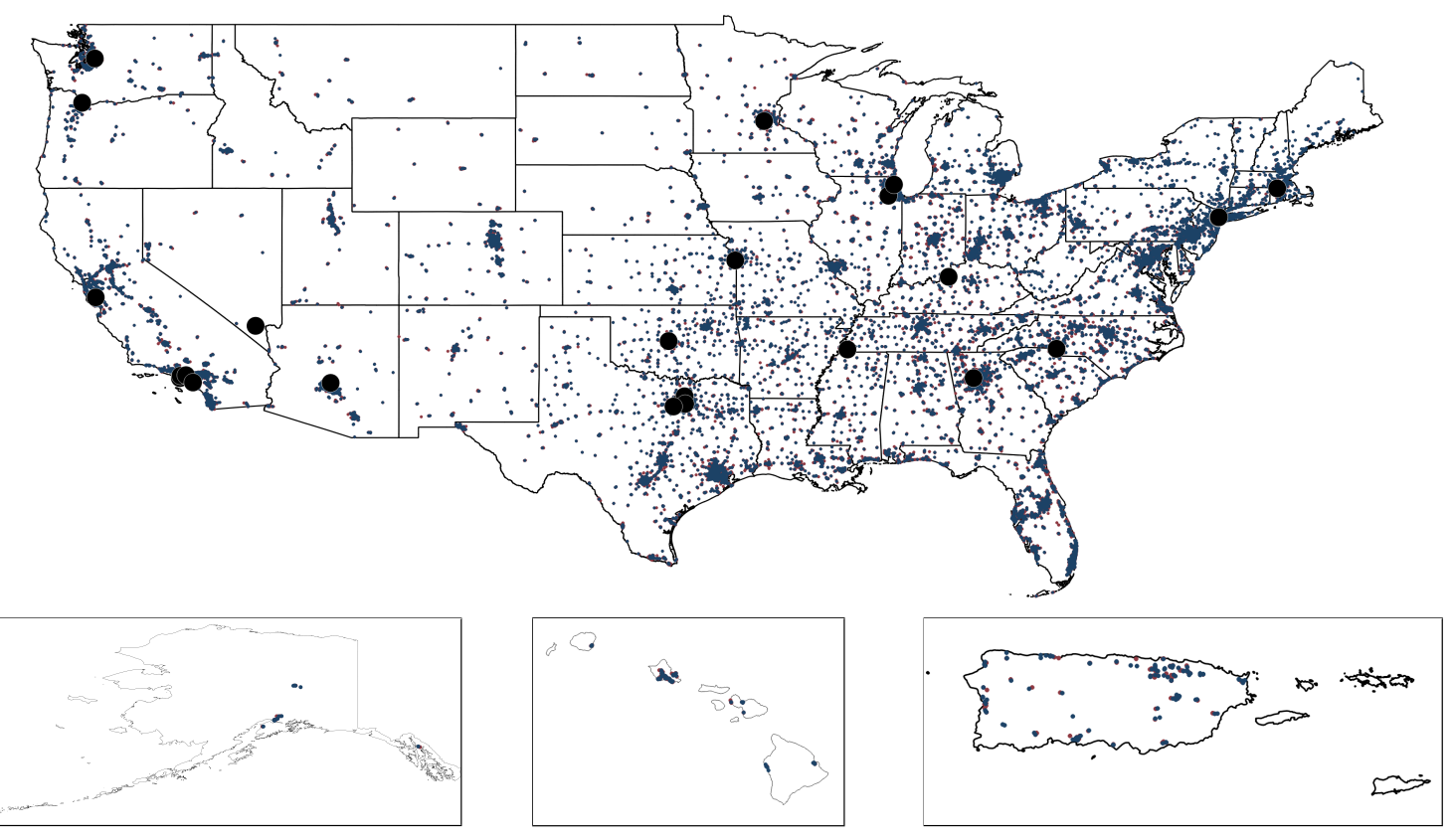


Table A.1

\section{Quarterly revenues and quarterly outlet visits}

This table presents results of ordinary least squares regressions using the logarithm of quarterly revenue as the dependent variable. Visits (Visitors) is the sum of the number of visits (visitors) across all stores per financial quarter. The sample comprises all nine financial quarters covered by the outlet visitor data and all firms in the outlet sample. The sample of treated outlets comprises 25,155 distinct outlets associated with a firm involved in a class action lawsuit. From the Securities Class Action Clearinghouse database, we drop lawsuits involving financial firms (two-digit NAICS industry 52), lawsuits targeting firms headquartered outside of the U.S., lawsuits filed before March 1, 2018, lawsuits filed after February 29, 2020, and lawsuits for which we cannot match outlets in SafeGraph. Standard errors, reported in parentheses, are clustered at the firm level. ${ }^{* * *},{ }^{* *}, *$ denote statistical significance at the $1 \%, 5 \%$, and $10 \%$ level, respectively.

\begin{tabular}{lcc}
\hline & \multicolumn{2}{c}{$\ln$ (Revenue) } \\
\cline { 2 - 3 } & $(1)$ & \\
\hline $\ln$ (Visits) & $0.5848^{* * *}$ & \\
& $(0.1667)$ & $0.6302^{* * *}$ \\
$\ln$ (Visitors) & & $(0.1452)$ \\
& & Yes \\
Firm FE & Yes & 223 \\
$\mathrm{~N}$ & 223 & 0.998 \\
$R^{2}$ & 0.997 & \\
\hline
\end{tabular}




\section{Table A.2}

\section{List of class action lawsuits in outlet sample}

This table presents a list of the class action lawsuits in the outlet-month panel as well as the number of treatment and control outlets for each class action lawsuit.The sample of treated outlets comprises 25,155 outlets associated with a firm involved in a class action lawsuit. From the Securities Class Action Clearinghouse database, we drop lawsuits involving financial firms (two-digit NAICS industry 52), lawsuits targeting firms headquartered outside of the U.S., lawsuits filed before March 1, 2018, lawsuits filed after February 29, 2020, and lawsuits for which we cannot match outlets in SafeGraph. We also drop outlets for which we cannot match control outlets. The control sample is constructed by selecting all outlets in the same ZIP code and six-digit NAICS industry as the treated outlets, resulting in a control comprising 123,129 outlets.

\begin{tabular}{lccc}
\hline Filing date & Company & \# treated outlets & \# control outlets \\
\hline 02mar2018 & Sprouts Farmers Market Incorporated & 334 & 1,212 \\
02mar2018 & Ulta Beauty, Inc. & 881 & 1,830 \\
08mar2018 & La Quinta Holdings Inc. & 888 & 7,869 \\
09mar2018 & Foot Locker, Inc. & 235 & 817 \\
23aug2018 & Jamba, Inc. & 653 & 4,013 \\
24aug2018 & SUPERVALU, Inc. & 17 & 33 \\
30aug2018 & Papa John's International, Inc. & 2,974 & 53,372 \\
04sep2018 & Skechers USA, Inc. & 369 & 1,946 \\
28sep2018 & Sprint Corporation & 2,657 & 7,117 \\
17oct2018 & CafePress Inc. & 2 & 11 \\
29oct2018 & Sonic Corp & 3,469 & 44,046 \\
02nov2018 & Walgreens Boots Alliance, Inc. & 2,422 & 2,612 \\
05nov2018 & Costco Wholesale Corporation & 461 & 1,773 \\
12dec2018 & Bojangles', Inc. & 663 & 4,435 \\
27dec2018 & YogaWorks, Inc. & 12 & 12 \\
25feb2019 & CVS Health Corporation & 2,602 & 2,451 \\
04mar2019 & Weight Watchers International, Inc. & 65 & 62 \\
01apr2019 & AT\&T Inc. & 3,625 & 8,291 \\
16apr2019 & Apple Inc. & 81 & 141 \\
22apr2019 & Sprint Corporation & 2,625 & 7,036 \\
30apr2019 & Papa Murphys Holdings, Inc. & 1,299 & 21,610 \\
20may2019 & Smart \& Final Stores, Inc. & 240 & 813 \\
26jun2019 & FedEx Corporation & 605 & 580 \\
16jul2019 & Barnes \& Noble, Inc. & 56 & 61 \\
15aug2019 & CVS Health Corporation & 2,601 & 2,445 \\
07nov2019 & Tandy Leather Factory, Inc. & 4 & 9 \\
03jan2020 & Tiffany \& Co. & 36 & 153 \\
11feb2020 & The Habit Restaurants, Inc. & 271 & 6,193 \\
28feb2020 & Aarons, Inc. & 155 & 176 \\
\hline
\end{tabular}


Table A.3

Filings of class action lawsuits over time

This table presents filings of class action lawsuits in the announcement return sample by calendar year and month. From the Securities Class Action Clearinghouse database, we drop lawsuits involving financial firms (two-digit NAICS industry 52), lawsuits involving firms headquartered outside of the U.S., lawsuits whose outcome are unknown ("ongoing"), and lawsuits that are remanded to another court. We also retain only lawsuits for which we can compute cumulative abnormal returns around the filing date, which requires non-missing stock return observations in the 12-day event window and at least 90 nonmissing return observations in the estimation window. The final sample comprises 3,322 class action lawsuits.

\begin{tabular}{|c|c|c|c|c|c|c|c|c|c|c|c|c|c|}
\hline \multirow[b]{2}{*}{ Year } & \multicolumn{12}{|c|}{ Month } & \multirow[b]{2}{*}{ Sum } \\
\hline & 1 & 2 & 3 & 4 & 5 & 6 & 7 & 8 & 9 & 10 & 11 & 12 & \\
\hline 1996 & 3 & 4 & 4 & 11 & 3 & 5 & 8 & 11 & 2 & 9 & 5 & 2 & 67 \\
\hline 1997 & 10 & 6 & 7 & 15 & 10 & 8 & 11 & 7 & 11 & 11 & 9 & 19 & 124 \\
\hline 1998 & 13 & 12 & 20 & 11 & 9 & 11 & 11 & 18 & 9 & 18 & 17 & 9 & 158 \\
\hline 1999 & 25 & 11 & 24 & 18 & 10 & 11 & 5 & 3 & 11 & 14 & 13 & 8 & 153 \\
\hline 2000 & 7 & 15 & 13 & 9 & 9 & 12 & 12 & 13 & 11 & 20 & 11 & 5 & 137 \\
\hline 2001 & 8 & 9 & 19 & 24 & 16 & 40 & 77 & 26 & 7 & 31 & 81 & 38 & 376 \\
\hline 2002 & 9 & 14 & 8 & 18 & 18 & 7 & 20 & 18 & 7 & 17 & 13 & 9 & 158 \\
\hline 2003 & 9 & 12 & 15 & 12 & 11 & 11 & 12 & 5 & 7 & 6 & 12 & 11 & 123 \\
\hline 2004 & 6 & 12 & 10 & 9 & 10 & 15 & 15 & 19 & 12 & 9 & 12 & 7 & 136 \\
\hline 2005 & 12 & 7 & 13 & 7 & 12 & 16 & 6 & 11 & 8 & 6 & 10 & 7 & 115 \\
\hline 2006 & 4 & 9 & 7 & 8 & 7 & 10 & 9 & 6 & 8 & 6 & 3 & 3 & 80 \\
\hline 2007 & 4 & 3 & 8 & 10 & 5 & 7 & 6 & 13 & 7 & 6 & 9 & 5 & 83 \\
\hline 2008 & 9 & 2 & 8 & 9 & 3 & 3 & 5 & 5 & 13 & 8 & 10 & 9 & 84 \\
\hline 2009 & 1 & 5 & 6 & 3 & 3 & 1 & 11 & 10 & 3 & 7 & 9 & 5 & 64 \\
\hline 2010 & 3 & 1 & 8 & 5 & 7 & 7 & 6 & 13 & 13 & 9 & 12 & 7 & 91 \\
\hline 2011 & 6 & 8 & 10 & 7 & 6 & 6 & 12 & 12 & 4 & 8 & 11 & 5 & 95 \\
\hline 2012 & 11 & 10 & 5 & 8 & 9 & 9 & 7 & 8 & 5 & 3 & 5 & 6 & 86 \\
\hline 2013 & 4 & 7 & 15 & 4 & 11 & 13 & 5 & 11 & 6 & 8 & 14 & 7 & 105 \\
\hline 2014 & 9 & 5 & 12 & 5 & 12 & 4 & 9 & 6 & 10 & 9 & 8 & 2 & 91 \\
\hline 2015 & 8 & 8 & 10 & 13 & 13 & 7 & 13 & 14 & 10 & 9 & 17 & 7 & 129 \\
\hline 2016 & 11 & 12 & 14 & 10 & 12 & 12 & 14 & 20 & 15 & 11 & 17 & 14 & 162 \\
\hline 2017 & 22 & 23 & 26 & 11 & 25 & 26 & 19 & 29 & 18 & 18 & 16 & 11 & 244 \\
\hline 2018 & 18 & 17 & 19 & 21 & 7 & 14 & 22 & 18 & 17 & 12 & 19 & 18 & 202 \\
\hline 2019 & 13 & 8 & 14 & 16 & 13 & 17 & 19 & 13 & 20 & 14 & 10 & 12 & 169 \\
\hline
\end{tabular}

